\title{
AN AERIAL RADIOLOGICAL SURVEY OF THE ROBERT EMMETT GINNA NUCLEAR POWER PLANT AND SURROUNDING AREA
}

ONTARIO, NEW YORK

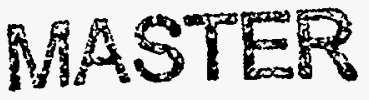




\section{DISCLAIMER}

This report was prepared as an account of work sponsored by an agency of the United States government. Neither the United States government nor an agency thereof, or any of their employees, makes a warranty, express or implied, or assumes legal liability or responsibility for the accuracy, completeness, or usefulness of any disclosed information, apparatus, product, or process, or represents that its use would not infringe privately owned rights. Reference herein to a specific commercial product, process, or service by trade name, trademark, manufacturer, or otherwise does not necessarily constitute or imply an endorsement, recommendation, or favoring by the United States government or an agency thereof. The views and opinions of the authors expressed herein do not necessarily state or reflect those of the United States government or an agency thereof.

This report has been reproduced directly from the best available copy.

This report is available to DOE and DOE contractors from the Office of Scientific and Technical Information, P.O. Box 62, Oak Ridge, TN 37831. Call (423) 576-8401 to obtain prices.

This report is available to the public from the National Technical Information Service, U.S. Department of Commerce, 5285 Port Royal, Springfield, VA 22161. Call (703) 487-4650 for information. 


\section{DISCLAIMER}

Portions of this document may be illegible in electronic image products. Images are produced from the best available original document. 


\title{
AN AERIAL RADIOLOGICAL SURVEY OF THE ROBERT EMMETT GINNA NUCLEAR POWER PLANT AND SURROUNDING AREA
}

\author{
ONTARIO, NEW YORK
}

DATE OF SURVEY: OCTOBER 7-11, 1995

A. E. Proctor

Project Scientist

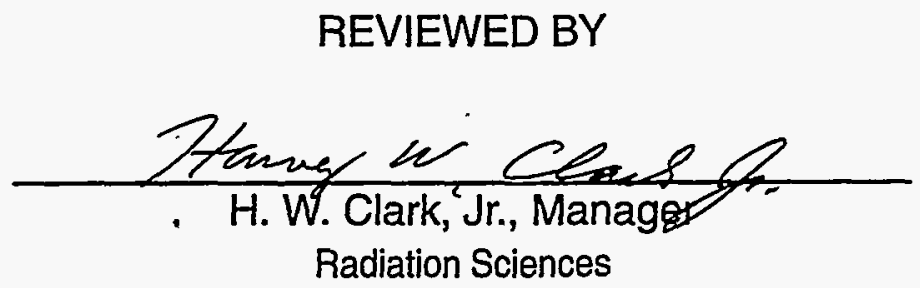

This Document is UNCLASSIFIED

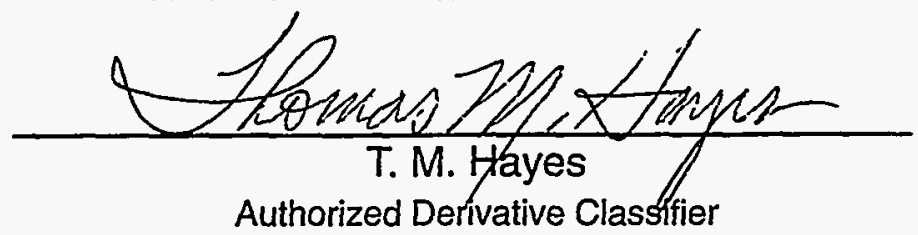

This work was performed for the U.S. Nuclear Regulatory Commission by EG\&G Energy Measurements, Inc., and Bechtel Nevada through an Economy Act Order transfer of funds to Contract Number DE-AC08-93NV11265 (EG\&G/EM) and Contract Number DE-AC08-96NV11718 (Bechtel Nevada) with the U.S. Department of Energy. 


\section{ABSTRACT}

Terrestrial radioactivity surrounding the Robert Emmett Ginna Nuclear Power Plant was measured using aerial radiological surveying techniques. The purpose of this survey was to document exposure rates near the plant and to identify unexpected, man-made radiation sources within the survey area. The surveyed area included land areas within a three-mile radius of the plant site. Data were acquired using an airborne detection system that employed sodium iodide, thallium-activated detectors. Exposure-rate and photopeak counts were computed from these data and plotted on aerial photographs of the survey area. Several ground-based exposure measurements were made for comparison with the aerial survey results. Exposure rates in the area surrounding the plant site varied from 6 to 10 microroentgens per hour. Man-made radiation (cobalt-60 within the plant site and cesium-137 directly over the reactor) was found at the plant site. In addition, small areas of suspected cesium-137 activity were found within the survey areas. Other than these small sites, the survey area was free of man-made radioactivity. 


\section{CONTENTS}

Abstract

\section{Sections}

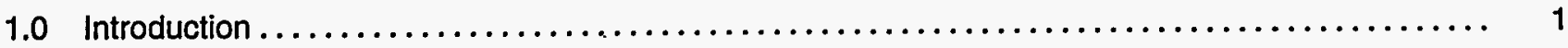

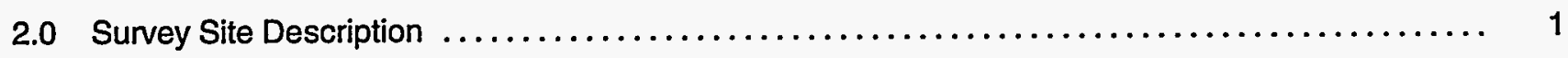

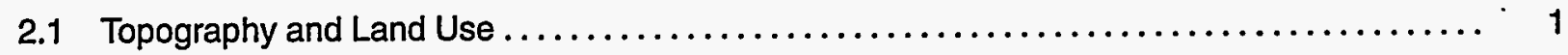

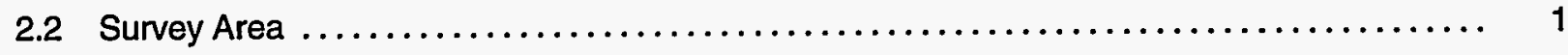

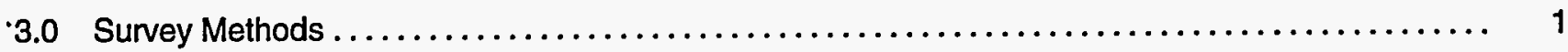

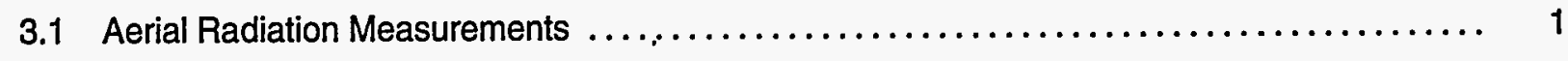

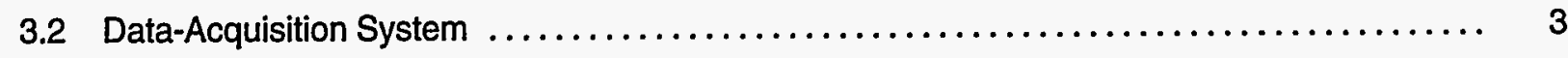

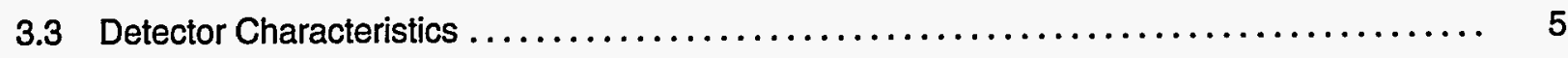

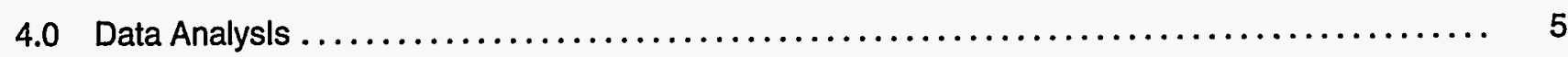

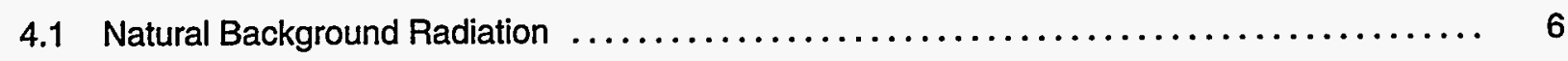

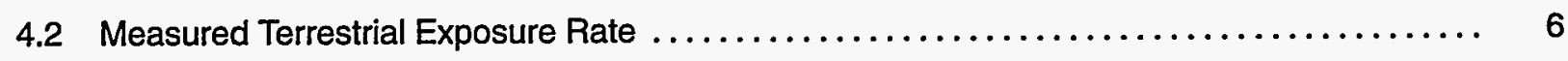

4.3 Identifying Sources of Man-Made Radiation from Aerial Survey Data .............. 8

4.4 Isotope-Specific Information from Aerial Survey Data $\ldots \ldots \ldots \ldots \ldots \ldots \ldots \ldots \ldots \ldots \ldots$

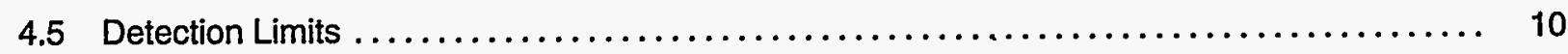

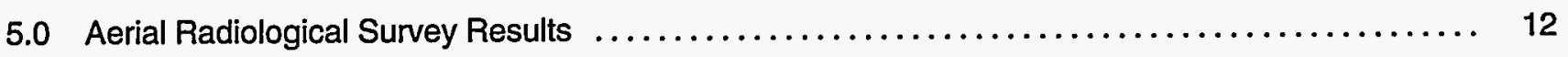

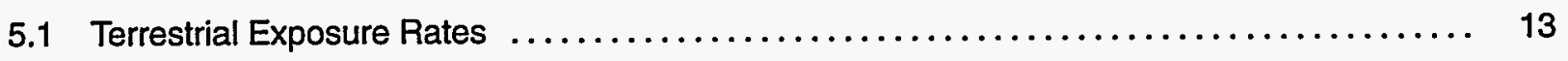

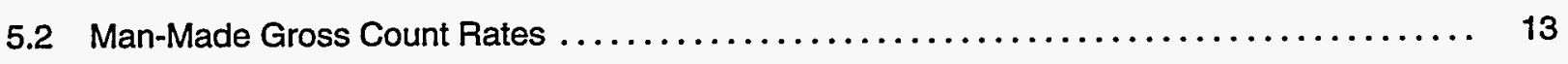

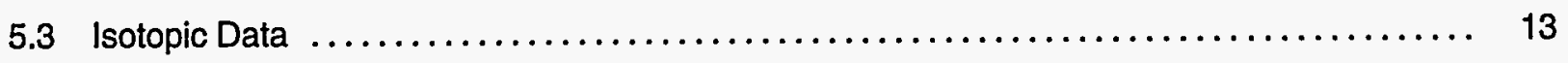

5.4 Residual Activity from the 1982 Rupture of a Steam Generator Tube .............. 15

\section{Figures}

1 Robert Emmett Ginna Nuclear Power Plant Survey Site $\ldots \ldots \ldots \ldots \ldots \ldots \ldots \ldots \ldots \ldots \ldots \ldots$

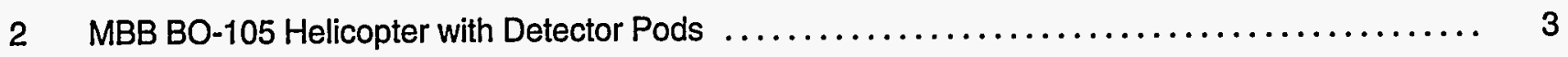

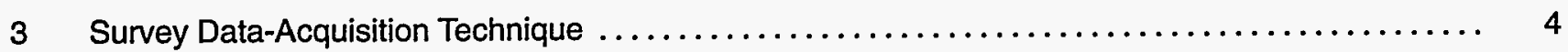

4 Typical Background Spectrum of the Survey Area $\ldots \ldots \ldots \ldots \ldots \ldots \ldots \ldots \ldots \ldots \ldots \ldots \ldots \ldots \ldots \ldots$

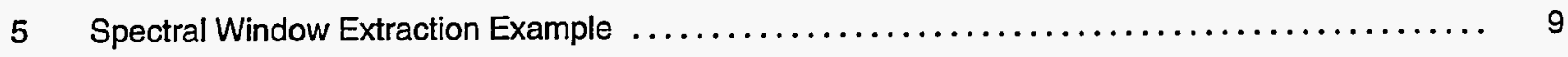


6 Distribution of Man-Made Radiation Data $\ldots \ldots \ldots \ldots \ldots \ldots \ldots \ldots \ldots \ldots \ldots \ldots \ldots \ldots \ldots \ldots \ldots$

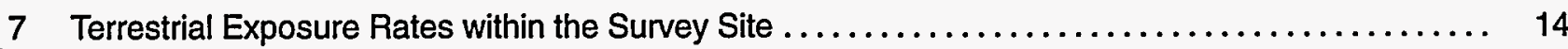

8 Man-Made Radiation within the Survey Site $\ldots \ldots \ldots \ldots \ldots \ldots \ldots \ldots \ldots \ldots \ldots \ldots \ldots \ldots \ldots$

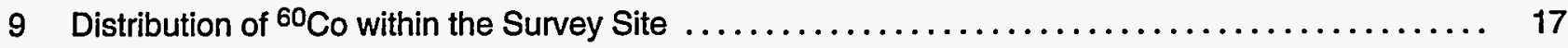

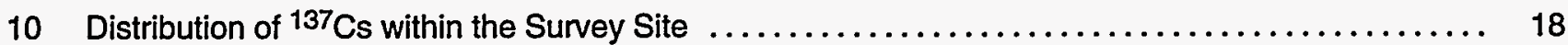

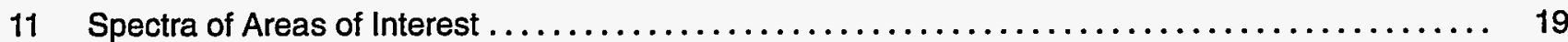

\section{Tables}

$1 \quad$ Approximate Detector Footprint Radius for Relative Count-Rate Contributions from Terrestrial Sources at a Survey Altitude of $150 \mathrm{ft}(46 \mathrm{~m}) \ldots \ldots \ldots \ldots \ldots \ldots \ldots \ldots \ldots$

2 Gamma-Ray Photopeak Identifications-Background within the Survey Area $\ldots \ldots \ldots \ldots \ldots \ldots$

3 Spectral Regions Used in Net Isotopic Count-Rate Calculations $\ldots \ldots \ldots \ldots \ldots \ldots \ldots \ldots \ldots$

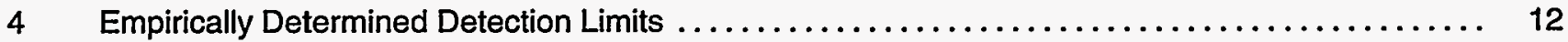

5 Comparison of Ground-Based (Pressurized lonization Chamber) and Aerial Survey Exposure Rates (Cosmic plus Terrestrial) $\ldots \ldots \ldots \ldots \ldots \ldots \ldots \ldots \ldots \ldots \ldots \ldots \ldots \ldots$

6 Gamma-Ray Photopeak Identifications-Spectrum A

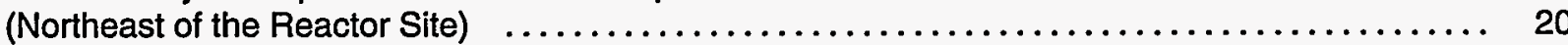

7 Gamma-Ray Photopeak Identifications-Spectrum B

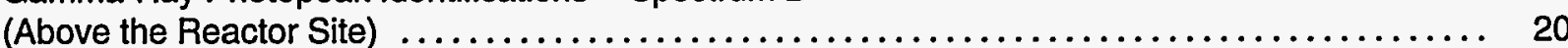

8 Gamma-Ray Photopeak Identifications-Spectrum C (Site along Lake Road)

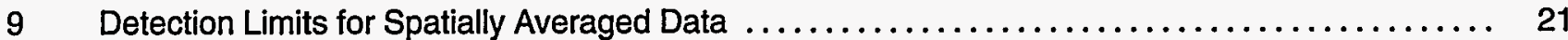

B-1 Calculated Critical Levels and Minimum Detectable Activity Versus Energy for Isotopic Analysis Based on a Realistic Background Spectrum

\section{Appendices}

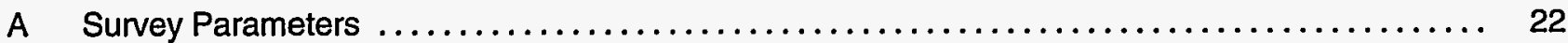

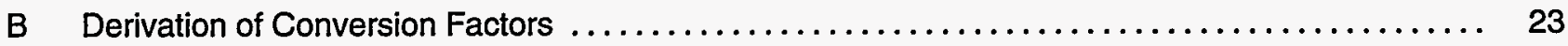

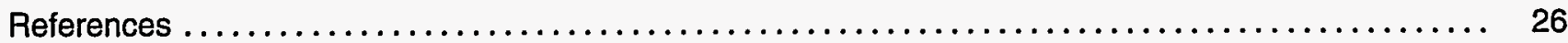




\subsection{INTRODUCTION}

An aerial radiological survey of the Robert Emmett Ginna Nuclear Power Plant site and surrounding area was conducted by the Remote Sensing Laboratory (RSL) for the U.S. Nuclear Regulatory Commission from October 7-11,1995. This survey is part of an ongoing effort to characterize radiation levels surrounding commercial nuclear power plants. Commercial plant sites are surveyed prior to initial criticality and periodically thereafter until the plant is decommissioned and the site returned to nonnuclear uses.

The Robert Emmett Ginna Plant, which began operating in 1970 , is a pressurized water reactor having a licensed rating of 1,520 megawatts thermal and 520 megawatts electrical. It is operated by the Rochester Gas and Electric Company. The site was surveyed in 1970 prior to reactor startup. The reactor was operational during a second survey performed in 1972. ${ }^{1}$ No known outages or other activities, which might have influenced the radiation measurements, occurred during the four-day survey.

The purpose of this survey was to measure the exposure rates near the plant and to determine if measurable contamination from the plant had spread outside the boundaries of the plant site. The survey consisted of aerial measurements of both natural and manmade gamma radiation emanating from the terrestrial surface. Results are reported as radiation isopleths superimposed on aerial photographs and topographic maps of the area.

The RSL performs various types of radiological surveys for the U.S. Department of Energy (DOE) and other customers. The RSL's capabilities include an airborne radiological surveillance system called the Aerial Measuring System (AMS). Since its inception in 1958, the AMS program has carried out radiological surveys of nuclear power plants, processing plants for nuclear materials, and research laboratories. The AMS aircraft have been deployed to nuclear accident sites and in searches for lost radioactive sources. The AMS aircraft also fly mapping cameras and multispectral camera arrays for aerial photography and thermal mappers for infrared imagery. Survey operations are conducted at the request of various federal and state agencies.

\subsection{SURVEY SITE DESCRIPTION}

The Robert Emmett Ginna Plant is located along the Lake Ontario shore, thirty miles east of Rochester, New York. Nearby towns include Ontario, Williamson, Sodus, and Sodus Point. Coordinates for the plant site are latitude $43^{\circ} 16^{\prime} 38^{\prime \prime} \mathrm{N}$ and longitude $77^{\circ} 18^{\prime} 30^{\prime \prime} \mathrm{W}$. Figure 1 shows the plant site. Appendix A provides a summary of the survey parameters.

\subsection{Topography and Land Use}

The topography consists of rolling terrain with moist soil. The types of vegetation range from pasture to forest. The majority of the trees are deciduous including many fruit trees in commercial orchards. Some swampy areas and areas covered with rotting vegetation were observed, but these comprised a small fraction of the survey area. The survey was completed in early fall while most of the leaves remained on the trees. There was no exposed rock except for what appeared to be man-made piles in several developed areas.

Except for several small towns, the area is sparsely populated. Land uses include agriculture (typically orchards), forest, resort (lake property), and homes on acreages. Industrial development is found along Route 104.

\subsection{Survey Area}

The plant is located on the shoreline of Lake Ontario. The survey area extends south from the shoreline in an approximate semicircle with a three-mile radius centered on the plant. An area extending $1,000-1,500 \mathrm{ft}(300-460 \mathrm{~m})$ over Lake Ontario was covered to facilitate later data reduction.

\subsection{SURVEY METHODS}

Standard aerial radiation survey techniques developed for large-area gamma radiation surveys were used. ${ }^{2}$ The survey methodology has been successfully applied to more than 300 individual surveys at various locations beginning in the late 1960 s.

\subsection{Aerial Radiation Measurements}

A Messerschmitt-Bolkow-Blohm (MBB) BO-105 helicopter with externally mounted detector pods, shown 


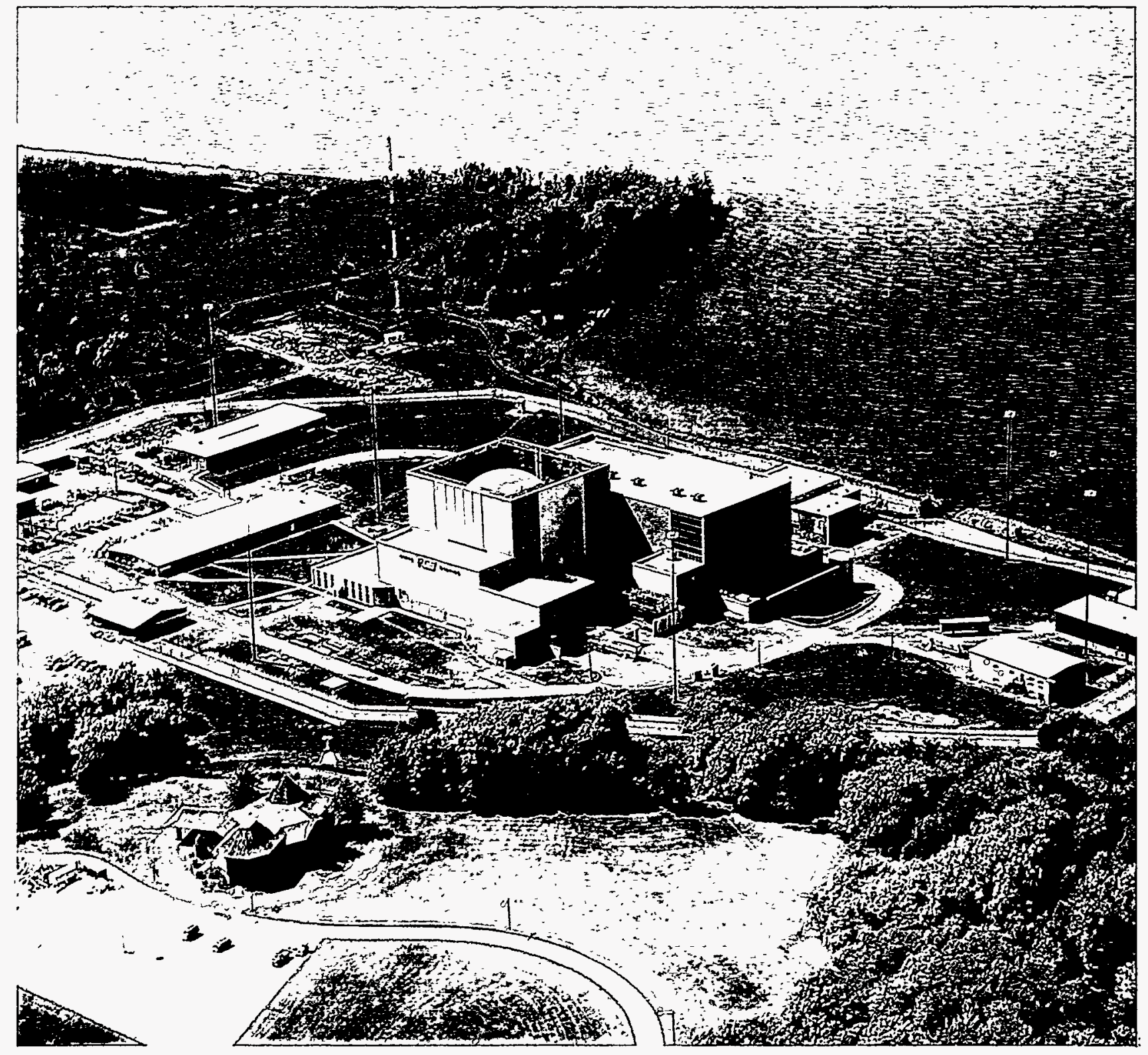

FIGURE 1. ROBERT EMMETT GINNA NUCLEAR POWER PLANT SURVEY SITE

in Figure 2, was used to collect the data. Important details of the aerial radiological survey process are illustrated in Figure 3. Gamma-ray spectral data were acquired at uniform spacing along a series of parallel lines that were flown in a north-south direction at an altitude of $150 \mathrm{ft}(46 \mathrm{~m})$ above ground level (AGL) and at a line spacing of $250 \mathrm{ft}(76 \mathrm{~m})$. Data were acquired continuously along these lines and recorded in onesecond intervals at an airspeed of 70 knots $(36 \mathrm{~m} / \mathrm{s})$. This one-second interval corresponds to a 118-ft $(36-m)$ data interval. During each interval, two gamma-ray spectra were detected from eight sodium iodide, thallium-activated, $\mathrm{Nal}(\mathrm{Tl})$, detectors. Other information such as air temperature, pressure, and altitude were also recorded during each interval.

The helicopter position was established by a Global Positioning System (GPS) operated in differential mode. Real-time aircraft positions were determined by an on-board GPS receiver, based on the measured position from GPS satellite data and a correction transmitted from a second GPS station located at a known position on the ground. The airborne GPS receiver provided continuous positional data to a microprocessor, which reformatted the data for use in RSL's airborne, computerized data-logging systems. 


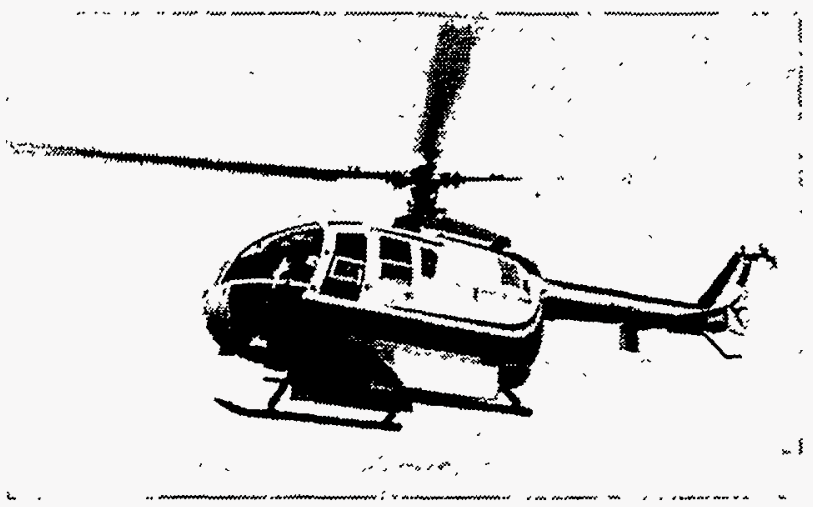

FIGURE 2. MBB BO-105 HELICOPTER WITH DETECTOR PODS

This on-board computer recorded the positional data and operated a steering indicator to aid the pilot in flying a set of equally spaced straight lines.

Real-time altitude measurements were made through a radar altimeter, which measured the return time for a pulsed signal and converted this delay to aircraft altitude. For altitudes up to $2,000 \mathrm{ft}(610 \mathrm{~m})$, the manufacturer's stated accuracy is $\pm 2 \mathrm{ft}(0.6 \mathrm{~m})$ or \pm 2 percent, whichever is greater. Altitude data were also recorded by the data-acquisition system so that variations in gamma signal strength caused by altitude fluctuations could be identified.

\subsection{Data-Acquisition System}

The detection system consists of two rectangular alu- . minum pods. Each pod contains four $2-\times 4-\times 16$-in down-looking and one $2-\times 4-\times 4$-in up-looking $\mathrm{Nal}(\mathrm{Tl})$ scintillation detectors. Pulse inputs from the eight 2- $\times 4-\times 16$-in detectors were summed and recorded as a spectrum, as discussed below. In addition, a spectrum from one of the $2-\times 4-\times 16$-in detectors was recorded separately to provide increased dynamic range when viewing high-radiation areas. Counts from the 2- $\times 4-\times 4$-in detector were recorded for possible use in correcting nonterrestrial radiation contributions. These $2-\times 4-\times 16$-in detectors were surrounded by thermal insulating foam and shielded on the top and sides with $0.03-$ in $(0.076-\mathrm{cm})$ cadmium and lead sheets. The 2- $\times 4-\times 4$-in detectors were shielded on the bottom and sides with the cadmium and lead sheets.

Spectral data were acquired and displayed in real time using specialized instrumentation that processes, stores, and displays spectral data. This system was developed for aerial radiological surveys and contains the necessary instrumentation in a single package. The system, called the Radiation and Environmental Data Acquisition and Recording, Version IV, (REDAR IV), system is a multi-microprocessor, portable dataacquisition, and real-time analysis system. ${ }^{3}$ it has been designed to operate in the severe environments associated with platforms such as helicopters, fixedwing aircraft, and various ground-based vehicles. The system displays the required radiation and system information to the operator, in real time, through the display of a CRT (cathode-ray tube) and through multiple readouts. Pertinent data were recorded on cartridge tapes for later analysis.

The REDAR IV system contains six subsystems: (a) two independent systems for collecting radiation data, (b) a general purpose data input/output (I/O) system, (c) a tape recording/playback system, (d) a CRT display system, (e) a real-time data-analysis system, and ( $f$ ) a ranging system with steering calculation and display capabilities. These subsystems, which are under the operator's control, handle functions including data collection, analysis, and display; positional and steering calculations; and data recording.

Two multichannel analyzers (MCAs) in the REDARIV system collect 1,024-channel, gamma-ray spectra (4.0 keV per channel) once every second during the survey operation. The primary MCA (for the eight-detector spectrum) has a usable dynamic range of up to about 100,000 cps corresponding to an exposure rate of about $1.5 \mathrm{mR} / \mathrm{h}$ at one meter AGL. Spectral information at high-count rates begins to degrade at approximately half of this rate; a single $\mathrm{Nal}(\mathrm{T} L)$ detector and second MCA are used in high-count-rate situations.

The data-acquisition system is calibrated to a $0-4,000-\mathrm{keV}$ energy range using gamma-ray sources of americium-241 $\left({ }^{241} \mathrm{Am}\right)$ at $60 \mathrm{keV}$, cobalt-60 $\left({ }^{60} \mathrm{Co}\right)$ at 1,173 and $1,332 \mathrm{keV}$, and cesium-137 ( ${ }^{137} \mathrm{Cs}$ ) at $661 \mathrm{keV}$. A 28-keV low-energy threshold is selected to minimize counts from the lower part of the continuum. The summed signal derived from the eight $\mathrm{Nal}(\mathrm{Tl})$ detectors was adjusted prior to processing by the analog-to-digital converter so that the calibration peaks appeared in preselected channels in the MCA of the data-acquisition system. 


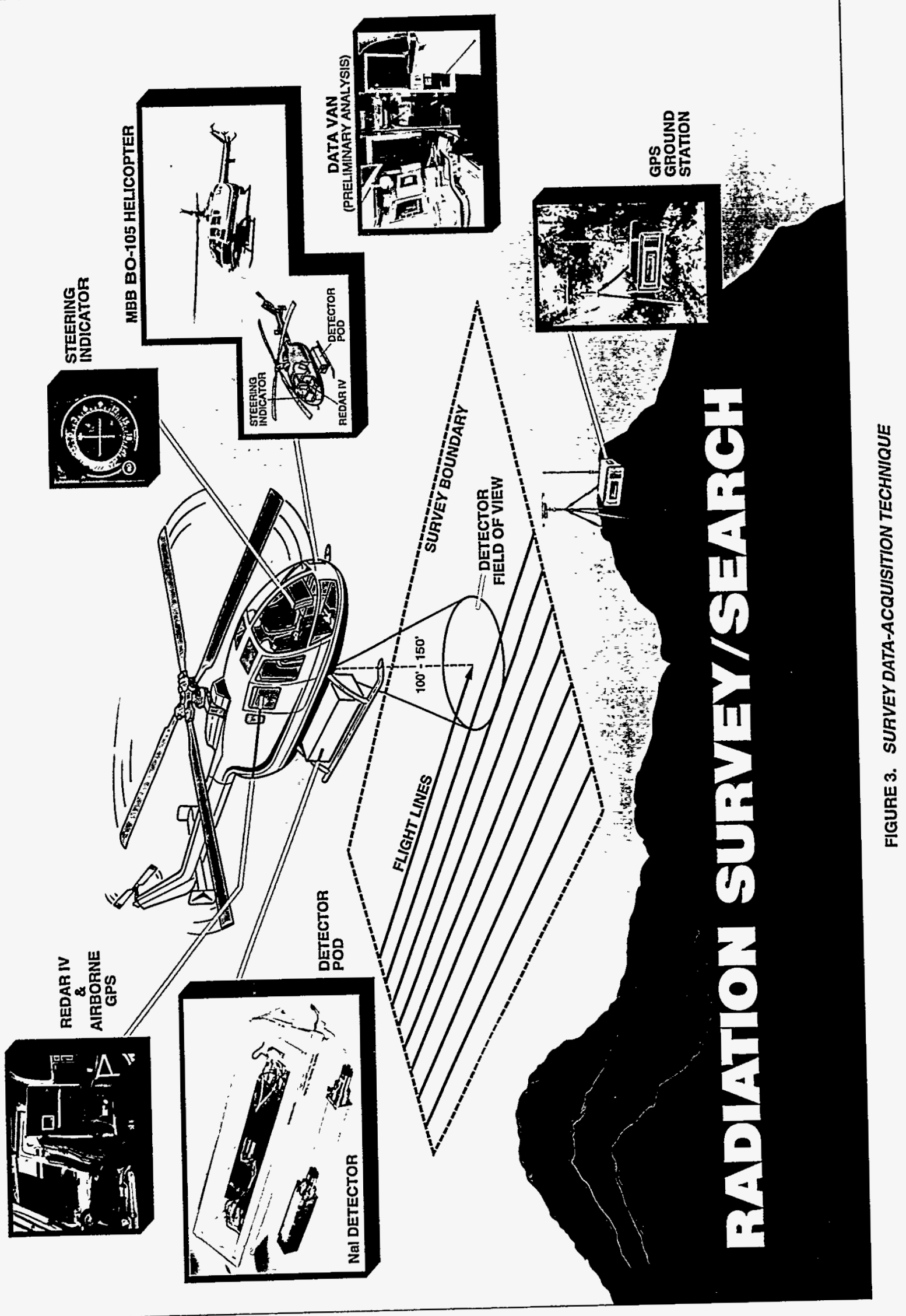


Because the resolution of $\mathrm{Nal}(\mathrm{Tl})$ crystals decreases with increasing energy, spectra are compressed to conserve storage space. Spectra are divided into three partitions where the detected photopeak width is approximately the same. Data in the first partition $(0-300 \mathrm{keV})$ are not compressed to permit stripping of low-energy photopeaks such as the $60-\mathrm{keV}$ photopeak from ${ }^{241} \mathrm{Am}$. The second partition $(300-1,620 \mathrm{keV})$ is compressed to $12 \mathrm{keV}$ per channel while the third partition $(1,620-4,000 \mathrm{keV})$ is compressed to $36 \mathrm{keV}$ per channel. The spectralcompression technique reduces the amount of data storage required by a factor of four.

Two full spectra, one spectrum containing data from the eight detectors and a second spectrum containing data from a single detector and related information such as position, time, and air temperature are continuously recorded every second. The REDAR IV system has two sets of spectral memories; each memory can accumulate four individual spectra. The two memories support continuous data accumulation: one memory stores data while the other memory transfers data to magnetic tape. At a survey speed of $70 \mathrm{knots}(36 \mathrm{~m} / \mathrm{s}$ ), 45 data sets were acquired for each mile of flight. The Ginna survey contained 39,000 data sets.

\subsection{Detector Characteristics}

The detector system was designed to sense terrestrial and airborne gamma radiation having energies between 20 and $4,000 \mathrm{keV}$. This energy range includes emitted gamma radiation from naturally occurring radionuclides and most man-made gamma radiation sources.

$\mathrm{Nal}(T l)$ detectors used in this survey are characterized by their variable sensitivity versus incident gamma energy and by a footprint size that is also energy-dependent. The variation in sensitivity with incident energy is a well-known characteristic of $\mathrm{Nal}(\mathrm{Tl})$ detectors. Detailed data on detector sensitivity can be obtained from the manufacturer. ${ }^{4}$ The dependence of the viewed footprint size with energy can be (approximately) modeled using Appendix B. Because of the large footprint, sources detected by aerial systems appear to be spread over a much larger area than would be indicated by ground-based measurements.
For uncollimated detectors, such as those used in this aerial survey, the source-to-detector distance and the attenuation by the air effectively limit the size of the viewed terrestrial area to a circular region centered beneath the detector. The size of the field of view is a function of the gamma-ray energy, the gamma-ray origin, and the detector response. Radionuclide activities on or in the soil and exposure rates normalized to one meter AGL are customarily reported but only as large-area averages. Activity inferred from aerial data for a source uniformly distributed over a large area compared to the field of view of the detectors is very good and generally agrees with ground-based measurements. However, activity for a point source, à line source, or a source activity less than the detector's field of view will be underestimated, sometimes by orders of magnitude. When this occurs, the aerial data simply serve to locate and identify such sources.

Apparent source-broadening makes comparison with ground-based measurements difficult. Radionuclides that occur as hot particles are averaged by the aerial detection system appearing as uniform large-area distributions. Ground surveys, however, would locate the hot particles within a smaller area and show the surrounding areas to be free of contamination. Table 1 contains estimates of the detection system's field of view or "footprint" size for several energies of interest.

Detector sensitivity is not constant throughout the footprint. The maximum sensitivity occurs directly beneath the detector; the sensitivity decreases with increasing horizontal distance between the source and airborne detector. Additionally, the incident gamma rays from even a monoenergetic source include scattered gamma rays once the incident radiation reaches the airborne detectors. Footprint sizes are, therefore, dependent on the source location: distributed in the soil, scattered by passing through air, inside a container, etc.

\subsection{DATA ANALYSIS}

Data processing was initiated in the field using a computer analysis laboratory installed in a mobile van located near the survey site. Data were examined before leaving the site, and a preliminary analysis was completed to ensure that the raw data were satisfactory.

Standard techniques for analyzing survey data were used; terrestrial exposure rates were computed from 

Table 1. Approximate Detector Footprint Radius for Relative Count-Rate Contributions from Terrestrial Sources at a Survey Altitude of $150 \mathrm{ft}(46 \mathrm{~m})$

\begin{tabular}{c|c|c|c}
\hline $\begin{array}{c}\text { Emitted } \\
\text { Gamma-Ray } \\
\text { Energy } \\
\text { (keV) }\end{array}$ & $\begin{array}{c}\text { Radius where } \\
\text { 99\% of Detected } \\
\text { Counts Originate } \\
\mathrm{ft}(\mathrm{m})\end{array}$ & $\begin{array}{c}\text { Radius where } \\
\text { 90\% of Detected } \\
\text { Counts Originate } \\
\mathrm{ft}(\mathrm{m})\end{array}$ & $\begin{array}{c}\text { Radius where } \\
\mathbf{5 0 \%} \text { of Detected } \\
\text { Counts Originate } \\
\mathrm{ft}(\mathrm{m})\end{array}$ \\
\hline 60 & $650(198)$ & $353(108)$ & $155(47)$ \\
200 & $850(259)$ & $435(133)$ & $178(54)$ \\
600 & $1,067(325)$ & $560(171)$ & $214(65)$ \\
1,500 & $1,715(523)$ & $772(235)$ & $260(79)$ \\
2,000 & $2,145(654)$ & $850(259)$ & $275(84)$ \\
3,000 & $2,862(872)$ & $1,007(307)$ & $308(94)$ \\
\hline
\end{tabular}

gross count data with a correction for variations in altitude. Man-made radioactivity, ${ }^{137} \mathrm{Cs}$, and ${ }^{60} \mathrm{Co}$ activity were determined through differences between total counts in appropriate spectral windows. ${ }^{5}$

\subsection{Natural Background Radiation}

Natural background radiation originates from (a) radioactive elements present in the earth, (b) airborne radon, and (c) cosmic rays entering the earth's atmosphere. Natural terrestrial radiation levels depend on the types of soil and bedrock immediately below and surrounding the point of measurement. Within cities, the levels are also dependent on the nature of the pavement and building materials. The gamma radiation originates primarily from the uranium and thorium decay chains and from radioactive potassium. Local concentrations of these nuclides produce radiation levels at the surface of the earth typically ranging from $1-15 \mu \mathrm{R} / \mathrm{h}$. Some areas with high concentrations of uranium and/or thorium in the surface minerals exhibit even higher-radiation levels, especially in the western states. ${ }^{6}$ The peaks listed in Table 2 were found in the natural background spectrum. Figure 4 shows a typical spectrum from natural background radiation within the Ginna survey area.

Isotopes of the noble gas radon are members of both the uranium and thorium radioactive decay chains. Radon can diffuse through the soil and may travel through the air to other locations; therefore, the level of airborne radiation due to these radon isotopes and their daughter products at a specific location depends on a variety of factors including meteorological conditions, mineral content of the soil, and soil permeability. Typically, airborne radon contributes from 1-10 percent of the natural background radiation.

Cosmic rays interact with elements of the earth's atmosphere and soil. These interactions produce an additional natural source of gamma radiation. Radiation levels due to cosmic rays vary with altitude and geomagnetic latitude. Typically, values range from 3.3 $\mu \mathrm{R} / \mathrm{h}$ at sea level in Florida to $12 \mu \mathrm{R} / \mathrm{h}$ at an altitude of $1.9 \mathrm{mi}(3 \mathrm{~km})$ in Colorado. ${ }^{7}$

\subsection{Measured Terrestrial Exposure Rate}

The measured count rate in the aircraft differs from the true terrestrial exposure rate due to background sources in the aircraft: (a) variation of cosmic radiation with altitude, (b) temporal variation in atmospheric radon concentrations, and (c) attenuation by the air of gamma rays emitted from the ground. Because the raw count-rate data have been found to vary, data from each flight are normalized to data measured over a test line that was measured at the beginning and end of each data-acquisition flight. This normalization is used to minimize the effects of natural airborne and background aircraft radiation. A test line west of the plant site, over farms and orchards, was selected for this survey. 
Table 2. Gamma-Ray Photopeak Identifications-Background within the Survey Area

\begin{tabular}{|c|c|}
\hline Energy (keV) & Identification \\
\hline 230 & ${ }^{208} \mathrm{TI}(239 \mathrm{keV}),{ }^{228} \mathrm{Ac}(209 \mathrm{keV}),{ }^{212} \mathrm{~Pb}(238 \mathrm{keV})$ \\
\hline 290 & ${ }^{228} \mathrm{Ac}(270 \mathrm{keV})$ \\
\hline 350 & ${ }^{228} \mathrm{Ac}(339 \mathrm{keV}),{ }^{214} \mathrm{Bi}(387 \mathrm{keV}, 389 \mathrm{keV})$ \\
\hline 511 (weak) & $208 \mathrm{TI}(511 \mathrm{keV}, 583 \mathrm{keV})$, annihilation \\
\hline 610 & ${ }^{214} \mathrm{Bi}(609 \mathrm{keV})$ \\
\hline 800 (weak) & ${ }^{228} \mathrm{Ac}(795 \mathrm{keV}),{ }^{208} \mathrm{TI}(760 \mathrm{keV})$ \\
\hline 920 & ${ }^{228} \mathrm{Ac}(911 \mathrm{keV}, 968 \mathrm{keV}),{ }^{214} \mathrm{Bi}(934 \mathrm{keV})$ \\
\hline 1,100 & ${ }^{214} \mathrm{Bi}(1,120 \mathrm{keV})$ \\
\hline 1,440 & $40 \mathrm{~K}(1,460 \mathrm{keV})$ \\
\hline 1,750 & ${ }^{214} \mathrm{Bi}(1,765 \mathrm{keV})$ \\
\hline 2,100 (broad) & ${ }^{214} \mathrm{Bi}(2,204 \mathrm{keV})$ \\
\hline 2,560 & ${ }^{208} \mathrm{Tl}(2,614 \mathrm{keV})$ \\
\hline
\end{tabular}

The terrestrial exposure rate can be calculated as follows:

Exposure Rate $=($ Conversion Factor $)(G C-B)$

$$
\cdot e^{-(A \cdot \text { altitude })}
$$

$G C$ is the gross count rate (sum of the contents of all spectrum channels) recorded by the REDAR IV system, and $A$ and $B$ are constants. $A$ is the site-specific atmospheric attenuation coefficient and has been found to be constant over the duration of a survey. $A$ is determined from data taken at multiple altitudes

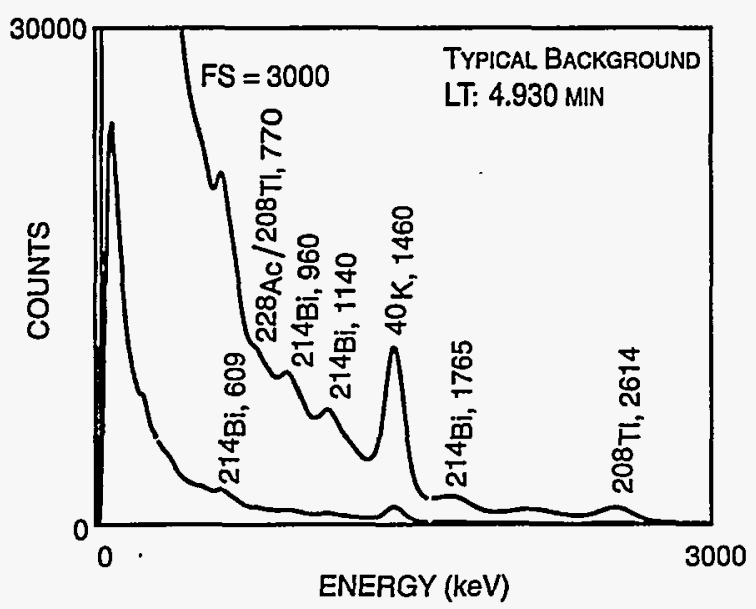

FIGURE 4. TYPICAL BACKGROUND SPECTRUM OF THE SURVEY AREA over the test line. $B$ represents the nonterrestrial background count rate and is calculated from test-line count rates measured before and after each survey data flight (using the previously determined value of $A$ ). An average value of $B$, the recorded altitude at each data interval, and the value of $A$ are used to correct measurements to yield the correct terrestrial gamma-emission rate. (Such a correction could be gamma-ray energy-dependent. At present, it is assumed that the relative contributions to the measured spectrum do not vary between the test line and the survey area, so an average correction is appropriate.)

A three-point sliding interval average was applied to gross count-rate data to reduce statistical fluctuations in the daita.

$$
C_{i, a v g}=\left(C_{i-1}+C_{i}+C_{i+1}\right) / 3
$$

$C_{i, a v g}$ is the averaged value at the $i$ th location, and $C_{i-1}, C_{i}$, and $C_{i+1}$ are consecutive, corrected gross count rates along a single flight line. Present analysis codes do not average nearest-neighbor data on adjacent flight lines; three-point averaging has been found to be adequate. The exposure rate is calculated from this averaged gross count rate. Three-point sliding interval averaging was applied to man-made and net 
isotopic data prior to calculating radiation contour maps.

The conversion factor, relating count rates to exposure rates, has been determined in several ways. It can be determined empirically by comparing groundbased, exposure-rate measurements with count rates from the airborne system. This was done for the Ginna survey using data obtained from comparative groundbased and aerial measurements of a well-characterized reference line. Two reference lines are maintained for survey calibration: one in Calvert County, Maryland, and a second in the Lake Mohave National Recreation Area near Las Vegas, Nevada. Data from the Calvert County test line were used for the Ginna survey because the Calvert County terrain is similar to the area covered by this survey. A conversion factor of $1.04 \times 10^{-3} \mu \mathrm{R} / \mathrm{h}(\mathrm{cps})^{-1}$. was used in the Ginna survey. 8,9

The terrestrial exposure-rate isopleth plots are also used as a quality check on the systematic variability of survey data. In particular, exposure-rate isopleths that fall along flight lines, especially along the initial or final lines of individual flights, indicate instability in the detection system. Such variations must be corrected before the data are used. If they are uncorrectable, the uncertainty (error bars) applied to the isopleth plots must be increased to eliminate obvious systematic variations.

\subsection{Identifying Sources of Man-Made Radiation from Aerial Survey Data}

Contaminated sites are located from isopleth maps based on a man-made radiation source algorithm, referred to as the man-made gross count (MMGC). This analysis provides a general overview of contamination within the survey area and also indicates which areas should be investigated further. The MMGC algorithm is based on several observations: (a) commonly occurring man-made sources emit gamma rays having energies less than $1,394 \mathrm{keV}$ while natural background sources emit gamma rays both below and above this threshold and (b) the spectrum continuum shape is relatively constant throughout the survey area. Moreover, gamma rays detected after they are scattered (e.g., emitted by sources buried in the soil or through atmospheric scattering) will contribute to the continuum at energies below their initial energies.

Assuming (a) a stable cosmic-ray emission rate; (b) a constant background due to the aircraft, airborne radon, and natural sources; and (c) a survey area where the gamma sources and soil composition change relatively slowly in comparison to the area contributing to the measured spectrum, the measured spectral shape is constant over the survey area. Experience has shown that these assumptions are reasonable within statistical uncertainties over large, uncontaminated survey areas. (Significant changes in the source characteristics will invalidate this assumption. For example, changes in the MMGC are seen in spectra acquired over different terrain and when airborne radon levels change.)

If there were no systematic errors in the detection system, the sum of all gamma radiation due to man-made sources would be the difference between the spectrum in question and a typical background spectrum. Unfortunately, systematic errors make this simple subtraction impractical. A more reliable comparison can be made using the ratios of the sum of all channel contents of the spectral region from $38-1,394 \mathrm{keV}$ (the region of man-made gamma emitters) to the sum of the spectral region from $1,394-3,026 \mathrm{keV}$ (the region containing mostly counts from naturally occurring gamma emitters).

$$
\begin{aligned}
M M G C= & \sum_{E=38 \mathrm{keV}}^{1394 \mathrm{keV}} C_{i} \\
& -\left[\text { Normalization } \cdot \sum_{E=1394 \mathrm{keV}}^{3026 \mathrm{keV}} C_{i}\right]
\end{aligned}
$$

$C_{i}$ represents the contents of spectrum channels corresponding to energies within the range of summation. The MMGC is the difference for a spectrum measured over an area containing man-made radionuclides, computed using the previously determined normalization constant. The constant is computed from data measured over areas free of contamination as follows: 


$$
\text { Normalization Constant }=\frac{\sum_{E=38 \mathrm{keV}}^{1394 \mathrm{keV}} C_{i}}{\sum_{E=1394 \mathrm{keV}}^{3026 \mathrm{keV}} C_{i}}
$$

The normalization constant is derived from the data of each flight to minimize the effects of airborne radon-222 ( $\left.{ }^{222} \mathrm{Rn}\right)$ and minor system characterization differences between flights.

\subsection{Isotope-Specific Information from Aerial Survey Data}

While the MMGC provides an indication of radioactive contamination, nuclide-specific information is important for such activities as identifying contamination sources and site remediation. Aerial survey data are also examined for spectral peaks due to various radionuclides that could be reasonably expected at the survey site: ${ }^{60} \mathrm{Co}$ and ${ }^{137} \mathrm{Cs}$. Annihilation radiation at $511 \mathrm{keV}$ was also examined as this line was prominent in previous survey data from boiling-water reactor sites. ${ }^{10}$ High-annihilation radiation arises from the nitrogen-16 $\left({ }^{16} \mathrm{~N}\right)$ produced in the reactor from an $(n, p)$ reaction on oxygen-16 $\left({ }^{16} \mathrm{O}\right)$. Because the Ginna Plant is a pressurized water reactor, this effect was not observed.

Spectral-stripping techniques were used to analyze aerial radiation data. (Peak fitting is not used because peak shapes from the $\mathrm{Nal}[\mathrm{Tl} l]$ detectors are broad and frequently overlap.) Spectra from areas of interest (usually those with significant MMGC levels) are analyzed by subtracting, channel-by-channel, a spectrum of a known background area. These spectra are sums of all spectral data acquired within the area:

$$
\begin{gathered}
\text { Difference Spectrum } i=C_{i, \text { site of interest }}-K_{\text {diff }} \\
\cdot C_{i, \text { background }}
\end{gathered}
$$

The $K_{\text {diff }}$ constant is selected to force the difference spectrum to zero at the high-energy side. Spectral peaks are readily visible in the difference spectrum (several such spectra are displayed later in this report). The presence of an identifiable spectral peak is considered to be a requirement for proceeding with isotopic isopleth plots. Once identified, contour plots of individual radionuclides are computed using two- or three-window spectral-stripping techniques on each data spectrum acquired during the survey as follows:

$$
\begin{aligned}
\text { Isotopic Net Count }= & \sum_{E=E_{1}}^{E_{2}} C(E)-(\text { Scaling Factor }) \\
& \cdot\left[\sum_{E=E_{3}}^{E_{4}} C(E)+\sum_{E=E_{5}}^{E_{6}} C(E)\right]
\end{aligned}
$$

$C(E)$ represents the spectrum channel contents, and $E_{i}$ is the limiting energy ranges of the windows. This technique is shown graphically in Figure 5. Again, the scaling factor is adjusted to set the isotopic net count to zero for data from known background regions. Spectral window ranges used for isotopic data presented in this report are shown in Table 3.

Survey data containing complex spectra may be subjected to multiple stripping calculations. Very complex spectra are analyzed by solving a set of linear equations relating the contribution of several gamma emitters to the overall spectrum. ${ }^{11}$ These techniques were not used in analyzing the Ginna survey data.

Nuclide-specific conversion factors take into consideration the isotopic-branching ratios, the spectral window analysis, and an assumed distribution of the source in the soil. The assumed distribution and soil attenuation at the gamma-ray energy being analyzed clearly affect the calibration. An assumed distribution

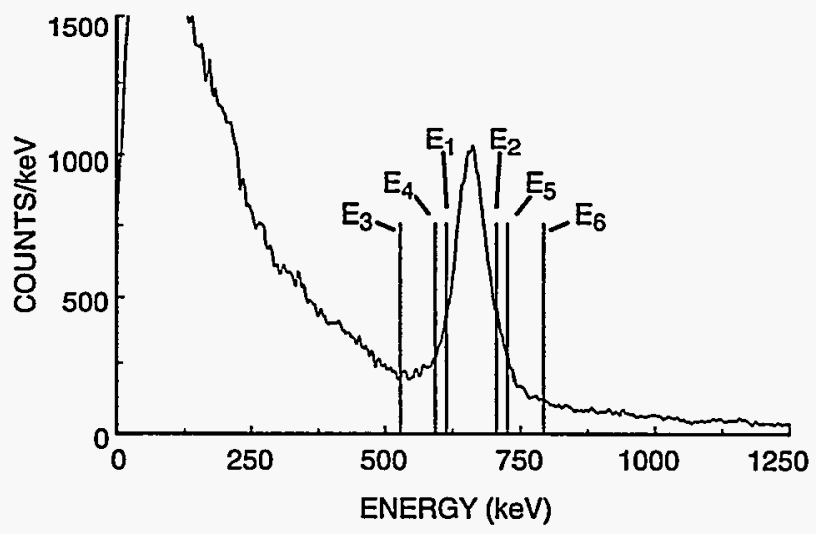

FIGURE 5. SPECTRAL WINDOW EXTRACTION EXAMPLE 
Table 3. Spectral Regions Used in Net Isotopic Count-Rate Calculations

\begin{tabular}{c|c|c|c}
\hline Isotope & $\begin{array}{c}\text { Peak Region } \\
\text { (keV) }\end{array}$ & $\begin{array}{c}\text { First Background } \\
\text { Region } \\
\text { (keV) }\end{array}$ & $\begin{array}{c}\text { Second Background } \\
\text { Region } \\
\text { (keV) }\end{array}$ \\
\hline${ }^{137} \mathrm{Cs}$ & $590-734$ & $506-590$ & $734-794$ \\
${ }^{60} \mathrm{Co}$ & $1,094-1,394$ & $1,394-3,026$ & (not used) \\
\hline
\end{tabular}

of radionuclides is often a best estimate leading to an unavoidable uncertainty in the computed soil activity. Contamination may be dispersed on the surface with no contamination below the surface, or it may be distributed throughout the soil. The latter case has been found to be more probable. For the Ginna survey, an exponential distribution was assumed based on actual depth profile measurements of similar radionuclides. ${ }^{12}$ Calculation of conversion factors based on these distributions is discussed in Appendix B.

\subsection{Detection Limits}

Aerial radiological survey results provide information on radiation levels at the nuclear power plant site (generally well above background) and in the surrounding area (generally a relatively constant background). High levels of radiation within the plant site are expected; the plant operator usually has groundbased measurements of the site. Aerial radiological survey data provide a check on the extent of high levels of radiation near the site. Due to the large survey footprint, aerial data are only an approximate measure of the extent of site-based radioactivity. There are less costly means than aerial radiological surveys to determine that the exposure rate (ground-based radioactivity, etc.) within the site boundaries of a nuclear power plant is greater than that of the surrounding countryside.

Radioactivity in the off-site area surrounding the plant, especially from plant site emissions, is assumed to consist of large areas (compared to the survey detection footprint) of natural and man-made radioactivity. The surrounding area is too large (and possibly inaccessible) for ground-based measurements and is best examined using aerial survey data. Man-made radioactivity from plumes of material emitted from the plant site is of interest. Activity outside the plant boundary will likely be much less than activity inside the plant boundaries! Detection limits used in analyzing the Ginna survey data were established to identify the lowest practical off-site contamination levels.

Aerial radiological survey data consist of many single measurements of footprints distributed over the survey area. It has been found from previous surveys that the survey data always contain large regions of background radiation with a few anomalous locations (i.e., the reactor site). Knowing this, the survey data can be treated as a single, large data set for isotopic net counts and MMGC. The Ginna survey data contained approximately 40,000 observations, a population sufficiently large that statistical analysis can be applied. Specifically, minimum detectable activities can be estimated using methods similar to those developed by Currie. ${ }^{13}$ The following discussion can be applied to both MMGC and isotopic net count rates.

Currie defines two limits useful in analyzing survey data: (a) a critical level which is the minimum count rate where one would assume that data from a footprint are different from the background in the survey area and (b) a detection limit which is the minimum activity source that can reliably be detected. The critical level, $L_{C}$, is determined by considering the distribution of count rates in the background data set (generally all the survey area outside the immediate reactor site) such that a fraction of all measured (calculated) quantities in the background data are less than or equal to $L_{C}$. This level addresses "type 1 errors" (failures to detect anomalous data). If a measurement or group of measurements is above $L_{C}$, then this region of the survey requires further examination. $L_{C}$ is defined as follows:

$$
L_{C}=k \cdot \sigma
$$


The value of $\sigma$ is determined from the distribution of survey data. The value of $k$ is selected based on the integral of a normal distribution from minus infinity to $L_{C}$ such that a desired fraction (e.g., 99.9 percent) of the observations in the distribution of background data is less than $L_{C}$ assuming normally distributed data. Examination of actual distributions of survey data supports this assumption. A measured value exceeding $L_{C}$ would be assumed to indicate radiation above background within a specified confidence level.

$L_{C}$ should not be considered to be a dimensional quantity. Individually measured and/or computed values would be distributed around the "real" value (mean value). A single, measured observation equal to $L_{C}$ could arise from measuring a range of "actual" activity levels.

The detection limit, $L_{D}$, may be understood by considering a single measurement of one survey footprint. Multiple measurements of this footprint would yield a distribution of values with a centroid corresponding to the actual (mean) activity within the footprint. Assuming a normal distribution of measurement values, Currie defines $L_{D}$ as the minimum activity (centroid of the distribution of measurements) where a desired fraction of all single measurements will fall above $L_{C}$ :

$$
L_{D}=2 L_{C}+k^{2}
$$

Equation 8 is based on Currie's analysis for radiationcounting data (Poisson statistics). For example, greater than 99.9 percent of all measured and/or calculated values for any "detectable" source (whose activity is $L_{D}$ or greater) will be above $L_{C}$. The desired fraction (or percentage) of the cumulative distribution of observations is commonly referred to as the confidence level. This ensures that a source whose activity is equal to or greater than $L_{D}$ will "always" be detected. $L_{D}$ represents the lowest-activity level that the survey detection process will consistently find.

The lowest-radiation isopleth level in a typical contour plot would be set at (or near) $L_{C}$ while $L_{D}$ would be the stated minimum detectable activity. (Higher contours are customarily defined in terms of "levels per decade," leading to an approximate logarithmic scale.) Radionuclide activities determined from net count values, that are greater than $L_{C}$ but less than $L_{D}$ are reported although they are below the "detection limit" of the instrumentation.

Figure 6 shows the distribution of calculated MMGC values from the Ginna survey data after applying sliding interval averaging. This distribution deviates from a true normal distribution, but a usable statistical uncertainty equal to 345 was calculated assuming a normal distribution. Isotopic net count rates of ${ }^{137} \mathrm{Cs}$ and ${ }^{60} \mathrm{Co}$ were normally distributed around zero.

Empirically determined $L_{C}$ and $L_{D}$ for the Ginna survey were obtained from examining the distribution of data. Table 4 shows the levels obtained from the Ginna survey for 99.5 and 99.9 percent confidence levels. $L_{D}$ values refer to radioactive material uniformly distributed on the surface $\left(\mu \mathrm{Ci} / \mathrm{m}^{2}\right)$, uniformly distributed throughout the soil versus depth (pCi/g[u]), or exponentially distributed throughout the soil versus depth (pCi/g[e]).

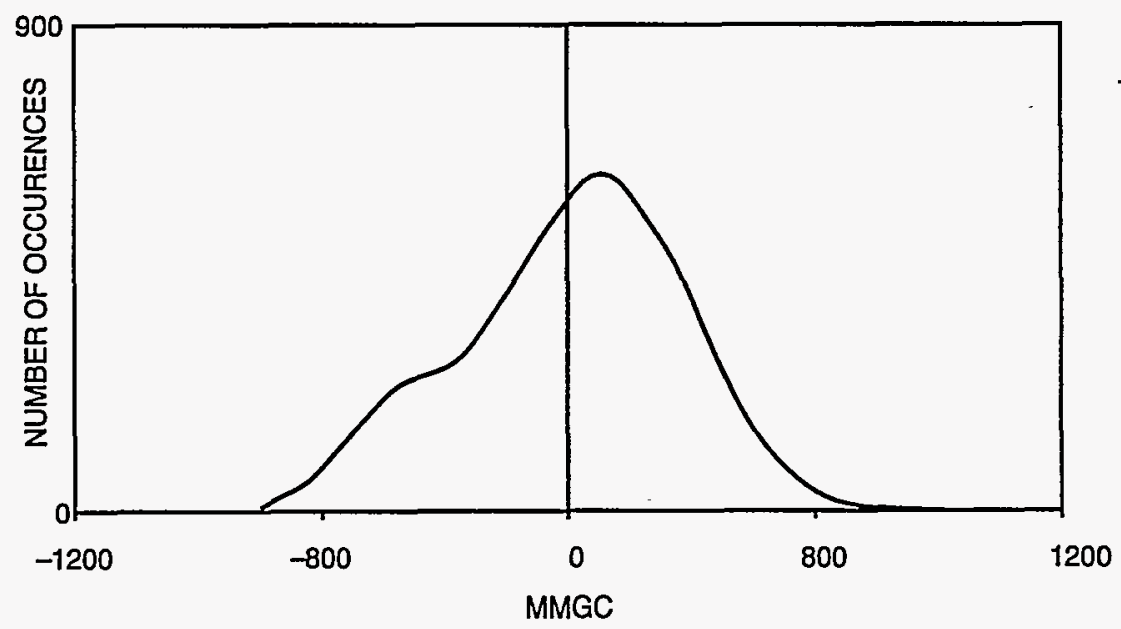

FIGURE 6. DISTRIBUTION OF MAN-MADE RADIATION DATA 
Table 4. Empirically Determined Detection Limits

\begin{tabular}{|c|c|c|c|c|c|}
\hline \multirow[b]{2}{*}{ Radionuclide } & \multirow[b]{2}{*}{$\begin{array}{c}\text { Statistical } \\
\text { Uncertainty } \\
\left.\text { ( } \sigma_{\text {survey data }}\right)\end{array}$} & \multicolumn{2}{|c|}{ Critical Level $\left(L_{c}\right)$} & \multicolumn{2}{|c|}{ Detection Limit ( $\left.L_{D}\right)$} \\
\hline & & $\begin{array}{c}99.5 \% \\
\text { Confidence } \\
\text { Levela }\end{array}$ & $\begin{array}{c}99.9 \% \\
\text { Confidence } \\
\text { Level }\end{array}$ & $\begin{array}{c}99.5 \% \\
\text { Confidence } \\
\text { Level }\end{array}$ & $\begin{array}{c}99.9 \% \\
\text { Confidence } \\
\text { Level }\end{array}$ \\
\hline MMGC & 345 & 886 net cps & 1069 net cps & 1780 net cps & 2149 net cps \\
\hline${ }^{60} \mathrm{Co}$ & 9.56 & 25 net cps & 30 net cps & $\begin{array}{l}0.029 \mu \mathrm{Ci} / \mathrm{m}^{2} \\
0.23 \mathrm{pCi} / \mathrm{g}(\mathrm{u})^{\mathrm{b}} \\
0.68 \mathrm{pCi} / \mathrm{g}(\mathrm{e})^{\mathrm{c}}\end{array}$ & $\begin{array}{l}0.032 \mu \mathrm{Ci} / \mathrm{m}^{2} \\
0.32 \mathrm{pCi} / \mathrm{g} \mathrm{(u)} \\
0.78 \mathrm{pCi} / \mathrm{g}(\mathrm{e})\end{array}$ \\
\hline${ }^{137} \mathrm{Cs}$ & 13.4 & 35 net cps & 42 net cps & $\begin{array}{l}0.064 \mu \mathrm{Ci} / \mathrm{m}^{2} \\
0.83 \mathrm{pCi} / \mathrm{g} \mathrm{(u)} \\
1.6 \mathrm{pCi} / \mathrm{g}(\mathrm{e})\end{array}$ & $\begin{array}{l}0.070 \mu \mathrm{Ci} / \mathrm{m}^{2} \\
0.90 \mathrm{pCi} / \mathrm{g}(\mathrm{u}) \\
1.7 \mathrm{pCi} / \mathrm{g}(\mathrm{e})\end{array}$ \\
\hline
\end{tabular}

The previous analysis provides a rigorous means to estimate trip levels and minimum detectable activity levels for the Ginna survey data. Unfortunately, application of statistical techniques leads to a problem of outliers. For example, basing $L_{C}$ on a 99.5 percent confidence level will ensure that 99.5 percent of measurements from background areas (assumed to be free of man-made radiation) will fall below $L_{C}$, and 0.5 percent of all background-area data will be above $L_{C}$ leading to an erroneous conclusion that 0.5 percent of the total survey area is contaminated. For a set of 40,000 observations, 0.5 percent represents 200 survey footprint measurements.

One solution to the outlier problem is setting $L_{C}$ at a value well above the background distribution but below the highest level seen over the nuclear power plant site. This approach has been used in the past, but the resulting large increase in minimum detectable activity would fail to detect low-level contamination. Another method deals with outliers by requiring spatial correlations between minimum activity data. Here it is assumed that individually measured values near $L_{C}$ are outliers if the data nearest the value in question were below $L_{C}$. Data values much higher than $L_{C}$ do not require spatial correlations to be valid.

Ginna survey radiation isopleth plots using $L_{C}$ values, based on 95, 99, 99.5, and 99.9 percent confidence levels, were examined for spatial correlations. Confidence-level plots of 95 and 99 percent contained many outliers and were judged not to be useful. Plots containing both 99.5 and 99.9 percent confidencelevel contours were examined, and it was found that both levels yield essentially identical features, with the 99.5 percent confidence-level plot containing numerous one-footprint "contours" that were judged to be statistical outliers. For example, the ${ }^{137} \mathrm{Cs}$ net rate plot contained about 150 such outliers.

The 99.9 percent confidence level was selected as the lowest-contour level presented on the Ginna isopleth plots. The probability that two adjacent data measured on two different flight lines are both outliers is $(0.001)^{2}=1 \times 10^{-6}$.

It is also possible to determine $L_{C}$ and $L_{D}$ from model calculations. Such calculations are useful in planning survey operations. Appendix B contains a table of predicted critical levels and detection limits for conditions similar to those of the Ginna survey.

\subsection{AERIAL RADIOLOGICAL SURVEY RESULTS}

Radiation contour plots were made of the Ginna site for exposure rate, MMGC, ${ }^{137} \mathrm{Cs}$, and ${ }^{60} \mathrm{Co}$. 


\subsection{Terrestrial Exposure Rates}

Figure 7 is a plot of the terrestrial exposure rates near the Ginna Plant site. The Lake Ontario shore is clearly visible-exposure rates are lower over large bodies of water than over land. Areas having high-exposure rates were located near the Ginna Plant site with the highest exposures occurring northeast of the reactor building. There were no other high-exposure-rate areas in the surrounding survey area. The large bullseyes around the plant site result from broadening effects discussed previously; the actual high-exposure-rate area was smaller than it appears. Smaller variations in exposure rate can be seen in the area surrounding the plant site. These correlate with differences in the terrain, which are clearly visible on the aerial photo.

Three ground-based, exposure-rate measurement locations are shown on the exposure-rate plot. These were acquired using a calibrated pressurized ion chamber." Ground-based and aerial survey exposure rates are compared in Table 5.

Exposure rates calculated from aerial survey data were slightly higher than ground-based rates. These differences can be attributed to the smaller measured footprint of the ground-based, pressurized ionization chamber; variations in the background spectrum; and measurement uncertainties in the aerial detection system.

\subsection{Man-Made Gross Count Rates}

MMGC contours for the Ginna survey are shown in Figure 8. High-MMGC areas were found only at the Ginna Plant site. The plot shows the 99.9 percent confidence level and higher rates. The shape of the highMMGC area is similar to that of the exposure rates shown in Figure 7 except that the area of high-MMGC rates extends further to the west.

\subsection{Isotopic Data}

Evidence of man-made and naturally occurring gamma emitters was found in the Ginna survey area.

\footnotetext{
- Reuter-Stokes, Model RSS-112, calibrated by the manufacturer.
}

Figure 9 shows the distribution of ${ }^{60} \mathrm{Co}$ where the lowest-level contour corresponds to a 99.9 percent confidence level. High levels of ${ }^{60} \mathrm{Co}$ are centered at the Ginna Plant site with the highest levels occurring northeast of the reactor building. The contour plot shows several small areas that are above the 99.9 percent confidence level; however, these appear to have no connection with the Ginna site. These areas contain too few counts to accumulate a spectrum. This may be due to local variations in terrain or to radionuclides present in the soil from fertilizers.

Figure 10 shows ${ }^{137} \mathrm{Cs}$ within the survey area. Only net count rates near the minimum detectable activity (99.9 percent confidence level) were seen. The largest area is centered at the Ginna site, but unlike the MMGC and ${ }^{60} \mathrm{Co}$ plots, the highest levels are seen directly over the reactor building. There are several smaller areas above the minimum detectable activity including one of possible interest on Lake Road, southeast of the Ginna Plant site. Smaller-size ${ }^{137} \mathrm{Cs}$ features are due to variations in ${ }^{137} \mathrm{Cs}$ from worldwide fallout remaining from atmospheric nuclear testing. (The ${ }^{137} \mathrm{Cs}$ extraction includes the vast majority of the worldwide ${ }^{137} \mathrm{Cs}$ fallout. It is significant only over those areas having above average variations.

Two other gamma emitters, silver-110m $\left({ }^{110 \mathrm{~m}} \mathrm{Ag}\right)$ and ${ }^{214} \mathrm{Bi}$, could yield apparent net ${ }^{137} \mathrm{Cs}$ counts in the three-window procedure used here. The ${ }^{137} \mathrm{Cs}$ plot was compared to one that mapped ${ }^{214} \mathrm{Bi}$, a naturally occurring radioactive element that emits a $609-\mathrm{keV}$ gamma ray. The presence of ${ }^{214} \mathrm{Bi}$ could cause a false ${ }^{137} \mathrm{Cs}$ net count. No correlation between ${ }^{137} \mathrm{Cs}$ and ${ }^{214} \mathrm{Bi}$ was found. Interference from ${ }^{110 \mathrm{~m}} \mathrm{Ag}$ is possible, and some evidence of other ${ }^{110 \mathrm{~m} A g}$ lines was found in the spectra.

Figure 11 contains spectra from areas of interest. Spectrum $A$ is a sum of the spectra over the "hot" area northeast of the reactor building. Spectrum $B$ is a sum of the spectra above the reactor building. Spectrum $C$ is a sum of the spectra over an area along Lake Road, southeast of the plant site containing detectable levels of ${ }^{137} \mathrm{Cs}$.

Table 6 lists the gamma-ray photopeak energies presented in Spectrum A with the probable radioisotopic identifications. Spectrum $A$ contains peaks due to ${ }^{214} \mathrm{Bi}$, ${ }^{152} \mathrm{Eu},{ }^{60} \mathrm{Co}$, and naturally occurring gamma emitters. 


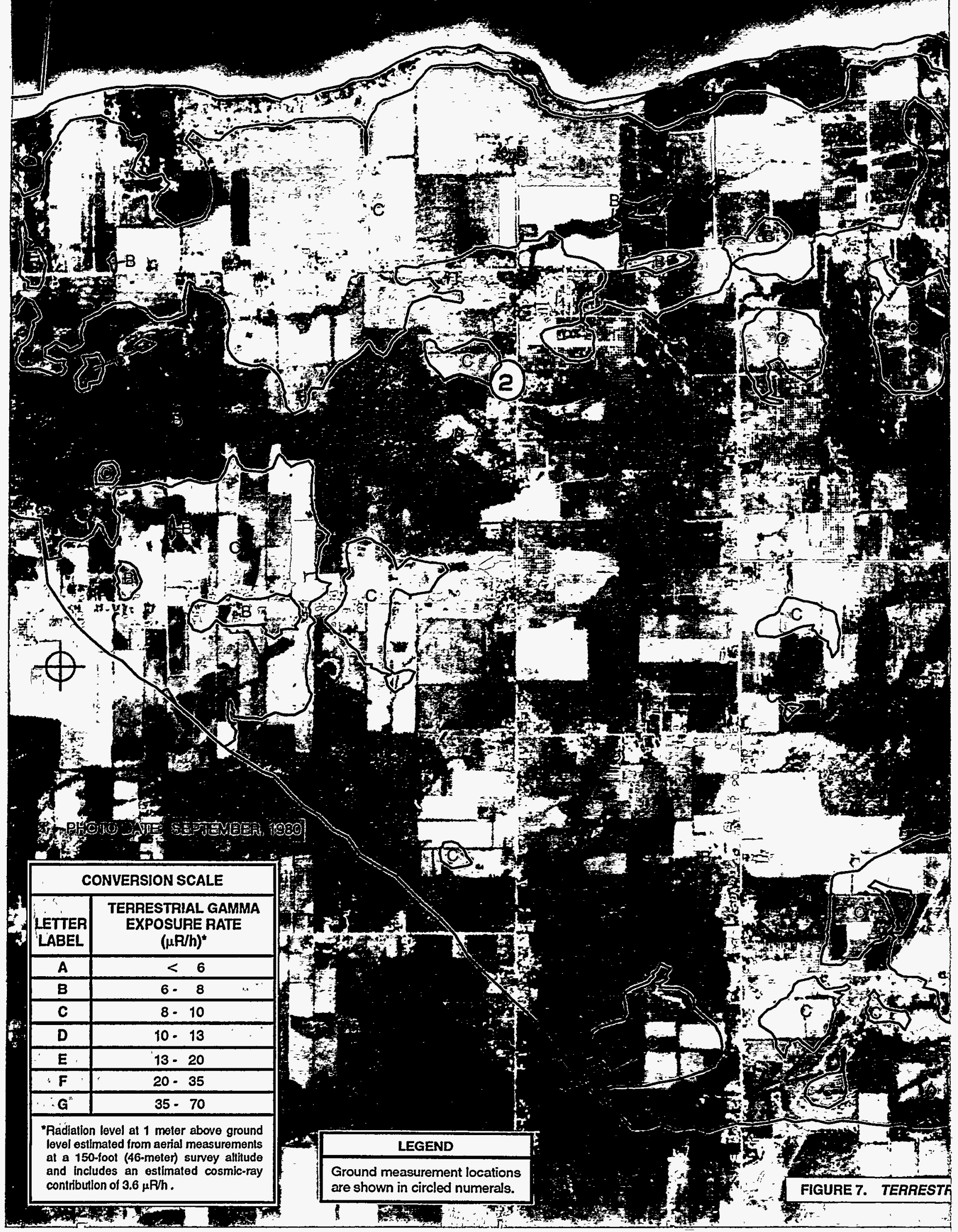




\begin{tabular}{|c|c|c|c|}
\hline \multirow[b]{2}{*}{$\begin{array}{l}\text { Point } \\
\text { Number }\end{array}$} & \multirow[b]{2}{*}{ Location } & \multicolumn{2}{|c|}{$\begin{array}{c}\text { Exposure Rate }(\mu \mathrm{R} / \mathrm{h}) \\
\pm 1 \text { Standard Deviation }\end{array}$} \\
\hline & & $\begin{array}{l}\text { Ground-Based } \\
\text { Measurement }\end{array}$ & $\begin{array}{l}\text { Aerial Survey } \\
\text { Measurement }\end{array}$ \\
\hline 1 & $\begin{array}{l}\text { Grass, trees, gravel drive ( } 7325 \text { Ontario } \\
\text { Creek Road) }\end{array}$ & $6.9 \pm 0.3$ & $8 . \pm 0.6$ \\
\hline 2 & $\begin{array}{l}\text { Landscaped lawn, shrubs, flowers } \\
\text { (7443 N. Lakeside) }\end{array}$ & $7.5 \pm 0.3$ & $8 . \pm 0.6$ \\
\hline 3 & $\begin{array}{l}\text { Along test line in farmer's field ( } 100 \mathrm{ft} \text { off } \\
\text { nearest paved road opposite } 7552 \text { Salmon } \\
\text { Creek Road) }\end{array}$ & $6.5 \pm 0.3$ & $\begin{array}{l}8.1 \pm 0.6 \text { (outside survey } \\
\text { area, data from test line) }\end{array}$ \\
\hline
\end{tabular}

a The cosmic contribution is assumed to be $3.6 \mu \mathrm{R} / \mathrm{h}$.

Table 7 lists the gamma-ray photopeak energies presented in Spectrum B with the probable radioisotopic identifications. Spectrum $B$ contains gamma lines due to ${ }^{60} \mathrm{Co},{ }^{54} \mathrm{Mn},{ }^{137} \mathrm{Cs}$, possibly ${ }^{110 \mathrm{~m}} \mathrm{Ag}$, and naturally occurring gamma emitters.

Table 8 lists the gamma-ray photopeak energies presented in Spectrum $\mathrm{C}$ with the probable radioisotopic identifications. Spectrum C was obtained from an area along Lake Road that contained a low concentration of ${ }^{137} \mathrm{Cs}$, visible in Figure 10 . This site is approximately one mile southeast of the Ginna Plant site. Evidence of naturally occurring gamma emitters was also found in Spectrum C.

\subsection{Residual Activity from the $\mathbf{1 9 8 2}$ Rupture of a Steam Generator Tube}

Radioactivity was released from the Ginna plant when a steam generator tube ruptured in 1982. According to information received from the U.S. Nuclear Regulatory Commission, material was projected $100 \mathrm{ft}$ above the reactor, where local winds carried it 100-200 yd eastward. ${ }^{14}$ As much activity as possible was collected by removing the snow covering the area surrounding the release. Residual activity in the soil was measured in 1982 and in 1989 by gamma spectroscopic examination of soil samples collected near the plant site.

Since evidence of the release was not seen in the initial data processing, spatial averaging was applied to the ${ }^{137} \mathrm{Cs}$ and ${ }^{60} \mathrm{Co}$ data. The area was divided into 750- $\times 750$-ft cells and all data falling into each cell-typically ten spectra per cell-were averaged. Averaging reduces the minimum detectable activity and the spatial resolution of the data. Minimum detectable activity values are shown in Table 9.

Spatially averaged ${ }^{137} \mathrm{Cs}$ and ${ }^{60} \mathrm{Co}$ plots were examined for indications of a release plume from the reactor site. The ${ }^{137} \mathrm{Cs}$ data were not usable; variations in the net area of the $609-\mathrm{keV}$ gamma line of ${ }^{214} \mathrm{Bi}$ in the survey data caused large random variations in the ${ }^{137} \mathrm{Cs}$ net activity. The ${ }^{60} \mathrm{Co}$ activity measurements also suffered from ${ }^{214} \mathrm{Bi}$ interference but not to as great an extent. Possible ${ }^{60} \mathrm{Co}$ deposition occurring between the "nominal plume centerline" of the 1982 release and North Ontario Center Road (from the reactor site to south of Lake Road and turning to the southwest beyond the intersection of Lake Road and North Ontario Center Road extending approximately $1500 \mathrm{ft}$ south of Lake Road) was found in radiation isopleth plots based on spatially averaged count rate data. Spectra collected over this area were summed. Examination of these spectra indicated weak, poorly resolved peaks near the 1,173 and $1,332 \mathrm{keV}$ gamma lines characteristic of ${ }^{60} \mathrm{Co}$. These spectral data were judged to be too ambiguous to state that the net ${ }^{60} \mathrm{Co}$ spectral window count rates in the aerial data were due to ${ }^{60} \mathrm{Co}$ contamination. Based on these results, ${ }^{60} \mathrm{Co}$ contamination in this area is suspected but cannot be proven. Additional 


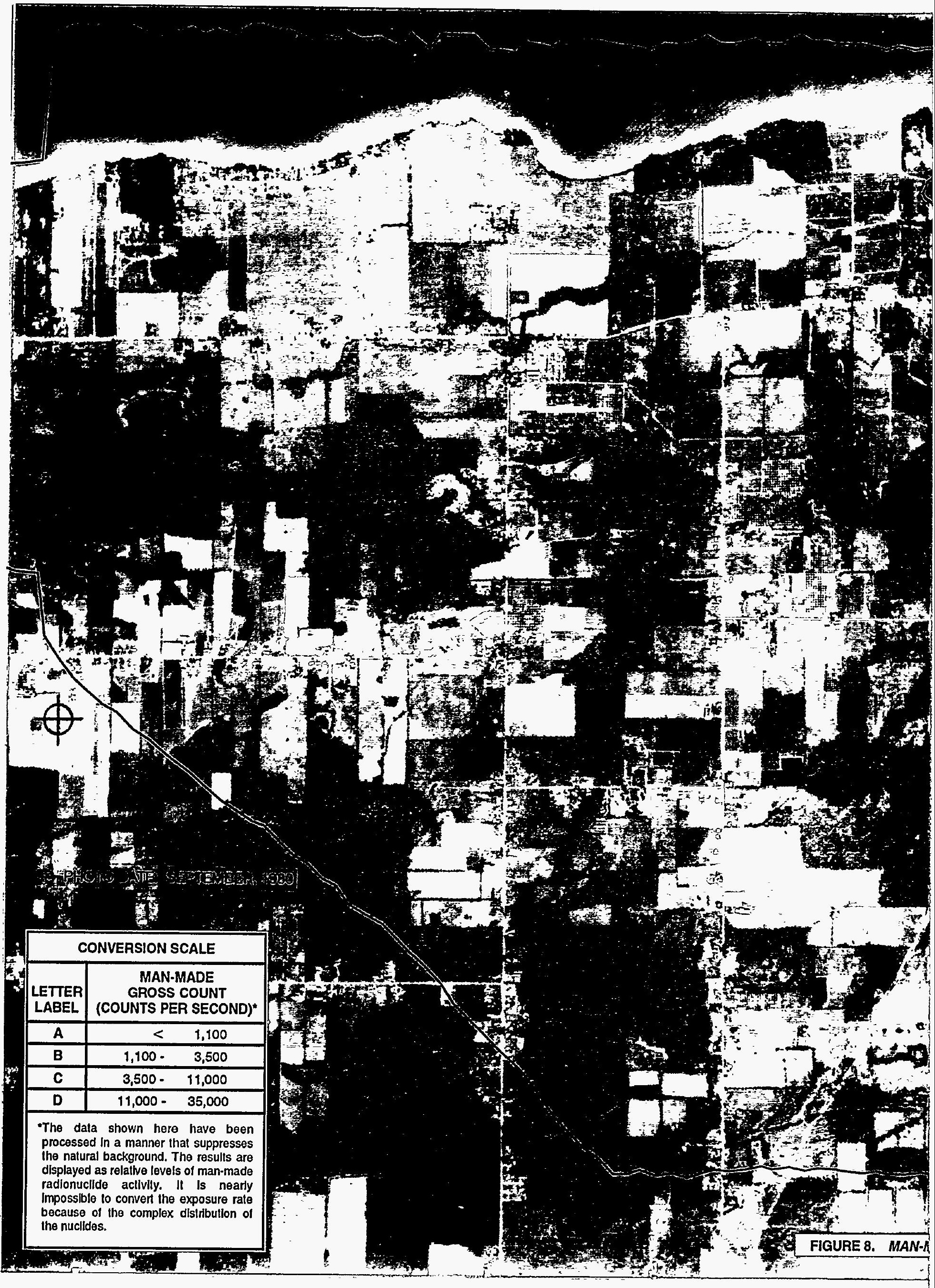




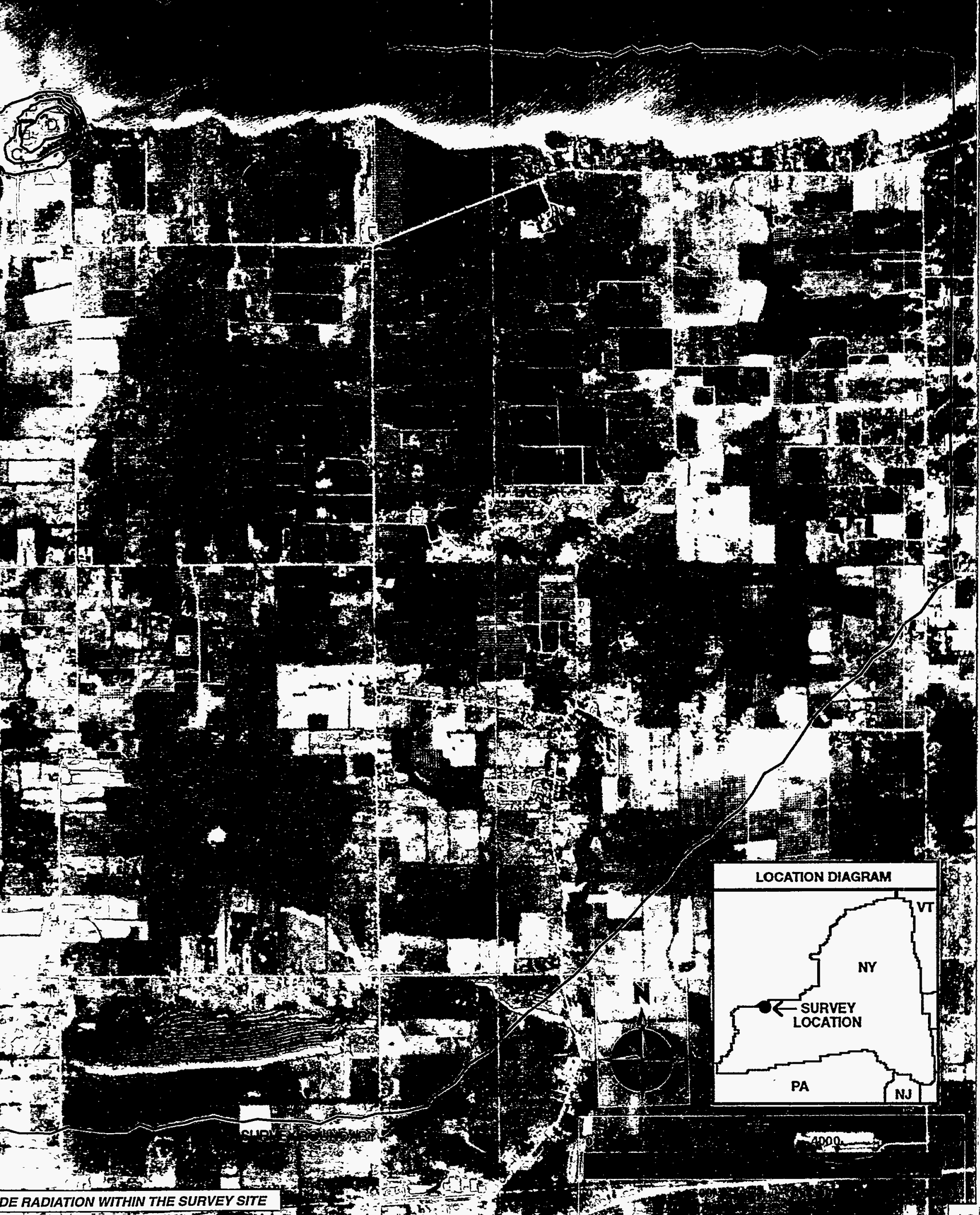




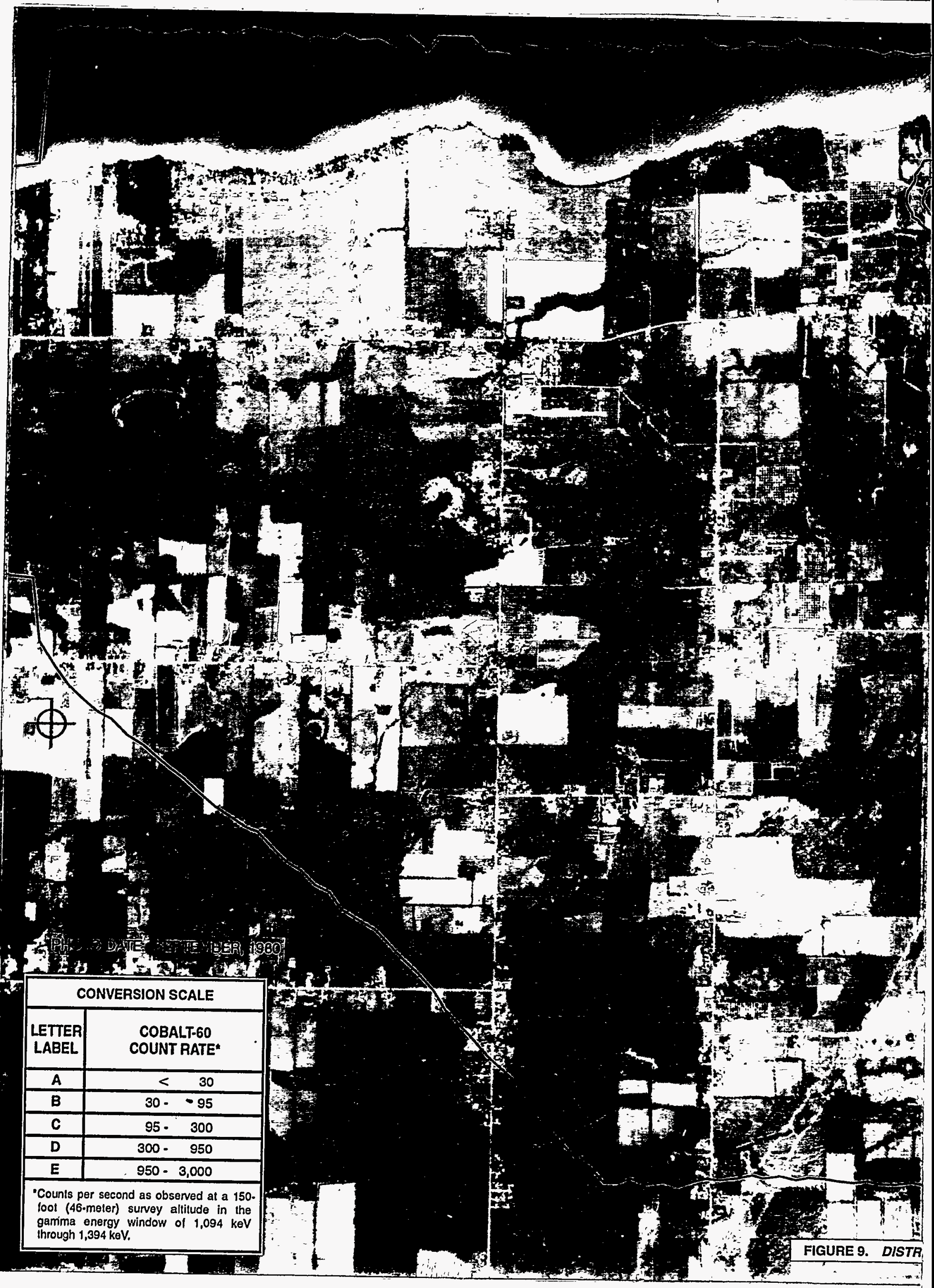




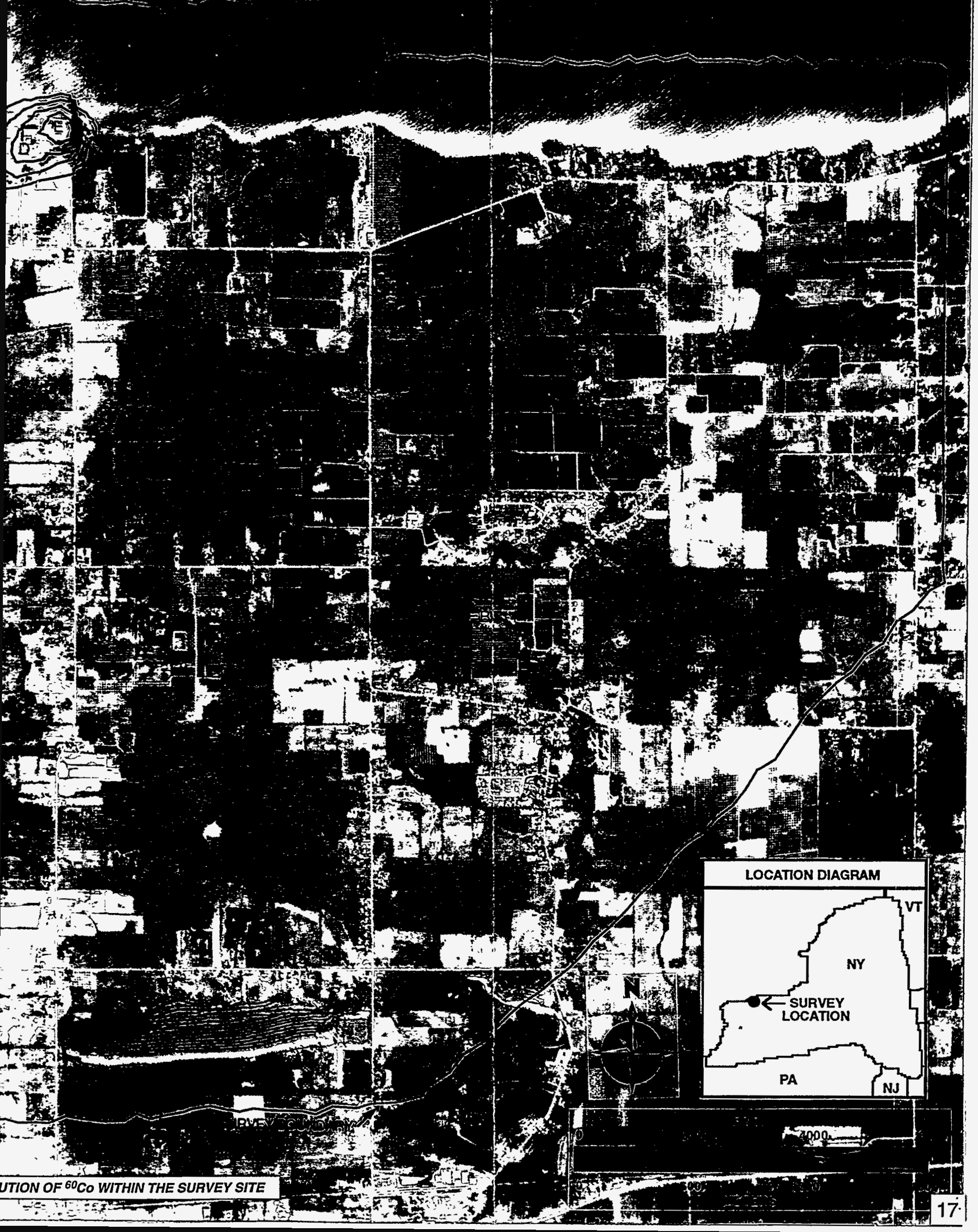




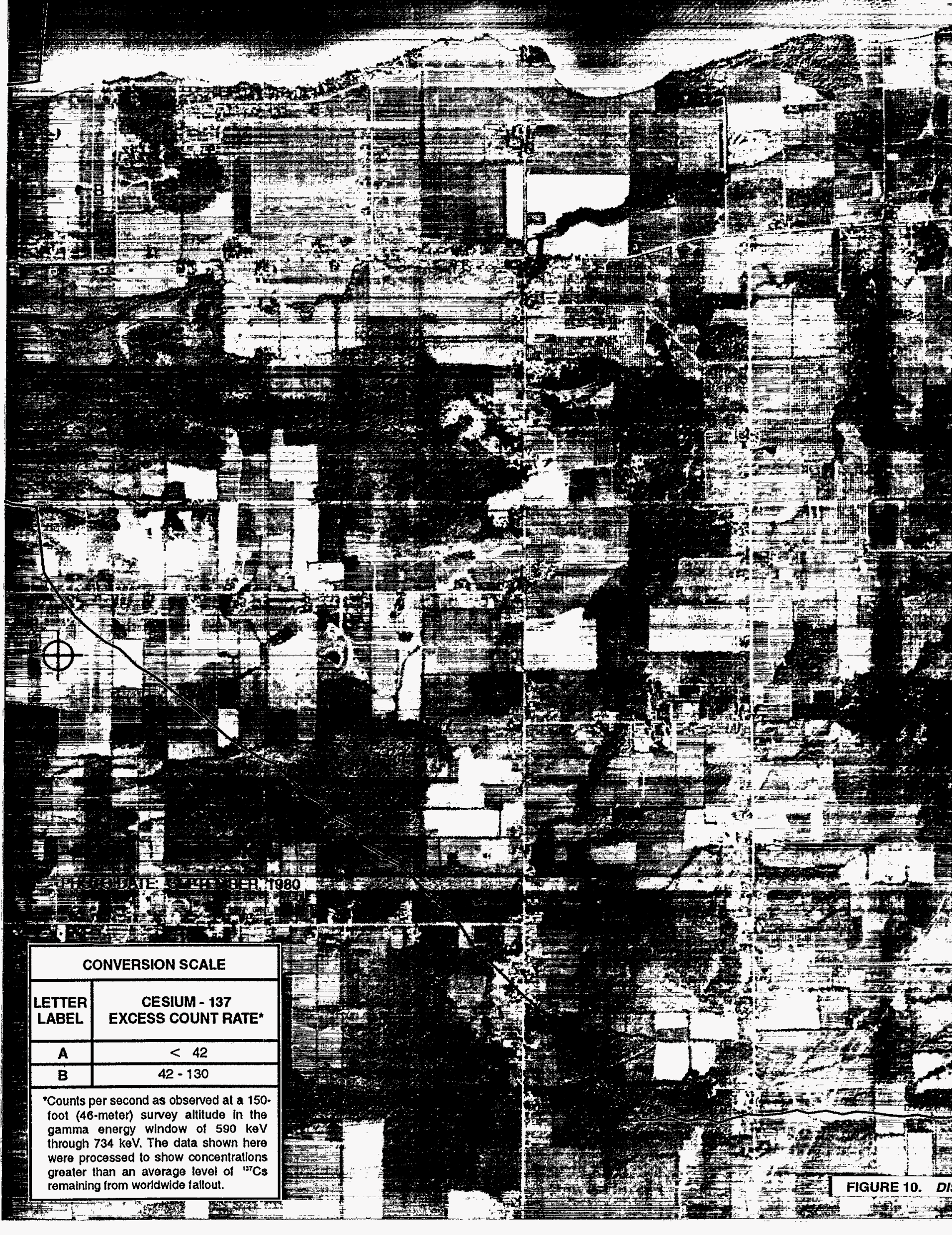




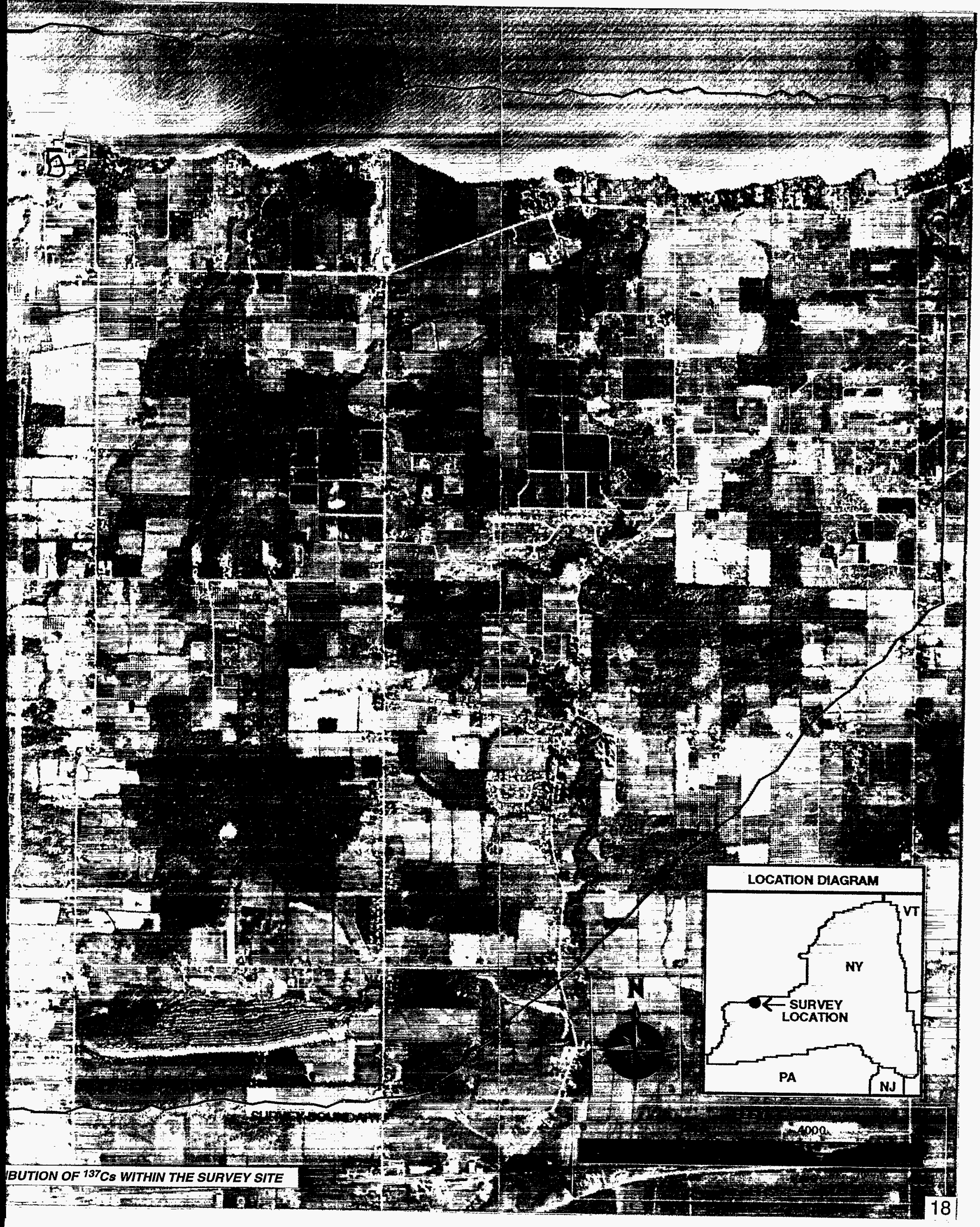


ground-based measurements may better quantify contamination in this area.

The ${ }^{60} \mathrm{Co}$ activities from aerial survey data located closer to the reactor site were compared with activities based on soil sample measurements ${ }^{15,16}$ from 1982

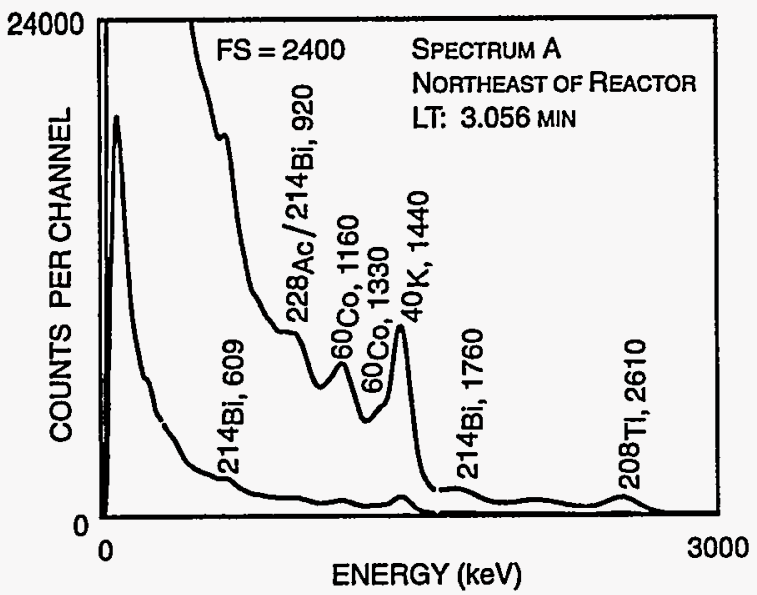

and 1989. Spectra from these areas contained indications of the 1,173- and 1,332-keV gamma lines. The ${ }^{60} \mathrm{Co}$ soil sample data (after correction for leaching and radioactive decay) were in agreement with these aerial survey results.

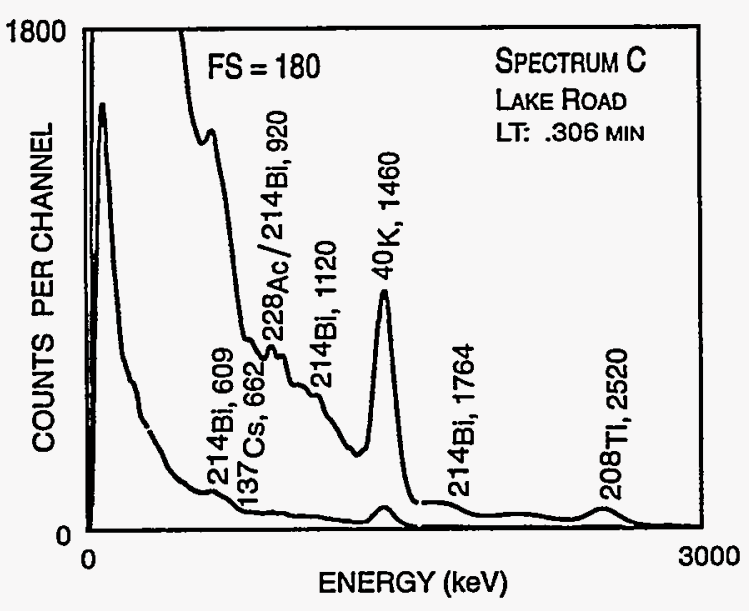

FIGURE 11. SPECTRA OF AREAS OF INTEREST 
Table 6. Gamma-Ray Photopeak Identifications-Spectrum A (Northeast of the Reactor Site)

\begin{tabular}{l|l}
\hline \multicolumn{1}{c|}{ Energy (keV) } & \multicolumn{1}{c}{ Identification } \\
\hline 580 (very weak) & ${ }^{208} \mathrm{TI}(583 \mathrm{keV})$ \\
609 & ${ }^{214} \mathrm{Bi}(609 \mathrm{keV})$ \\
780 (weak) & ${ }^{152} \mathrm{Eu}(779 \mathrm{keV}),{ }^{228} \mathrm{Ac}(795 \mathrm{keV})$, \\
920 (multiplet) & ${ }^{228} \mathrm{Ac}(911 \mathrm{keV}),{ }^{214} \mathrm{Bi} .(934 \mathrm{keV})$ \\
960 (multiplet) & ${ }^{152} \mathrm{Eu}(964 \mathrm{keV}),{ }^{228} \mathrm{Ac}(968 \mathrm{keV})$ \\
1,160 (broad peak) & ${ }^{152} \mathrm{Eu}(1,112 \mathrm{keV}),{ }^{60} \mathrm{Co}(1,173 \mathrm{keV}),{ }^{214} \mathrm{Bi}(1,120 \mathrm{keV})$ \\
1,330 (on side of $1440-\mathrm{keV}$ peak) & ${ }^{60} \mathrm{Co}(1,332 \mathrm{keV})$ \\
1,440 & ${ }^{152} \mathrm{Eu}(1,408 \mathrm{keV}),{ }^{40} \mathrm{~K}(1,460 \mathrm{keV})$ \\
1,760 (broad peak) & ${ }^{214} \mathrm{Bi}(1,765 \mathrm{keV})$ \\
2,610 (broad peak) & $208 \mathrm{Tl}(2,614 \mathrm{keV})$ \\
\hline
\end{tabular}

Table 7. Gamma-Ray Photopeak Identifications-Spectrum B (Above the Reactor Site)

\begin{tabular}{|c|c|}
\hline Energy (keV) & Identification \\
\hline 590 (weak) & ${ }^{208} \mathrm{Tl}(583 \mathrm{keV})$ \\
\hline 609 (weak) & ${ }^{214} \mathrm{Bi}(609 \mathrm{keV})$ \\
\hline 660 (weak) & ${ }^{137} \mathrm{Cs}(662 \mathrm{keV}),{ }^{110 \mathrm{~m}} \mathrm{Ag}(658 \mathrm{keV})$ \\
\hline 820 (weak multiplet) & ${ }^{54} \mathrm{Mn}(834 \mathrm{keV}),{ }^{58} \mathrm{Co}(810 \mathrm{keV}),{ }^{110 \mathrm{~m} A g}(764 \mathrm{keV})$ \\
\hline 850 (weak multiplet) & ${ }^{208} \mathrm{TI}(861 \mathrm{keV}),{ }^{110 \mathrm{~m}} \mathrm{Ag}(885 \mathrm{keV})$ \\
\hline 1,060 & \\
\hline 1,170 & ${ }^{60} \mathrm{Co}(1,173 \mathrm{keV})$ \\
\hline 1,330 & ${ }^{60} \mathrm{Co}(1,332 \mathrm{keV}),{ }^{110 \mathrm{~m}} \mathrm{Ag}(1,384 \mathrm{keV})$ \\
\hline 1,460 (weak) & ${ }^{40} \mathrm{~K}(1,460 \mathrm{keV}),{ }^{110 \mathrm{~m}} \mathrm{Ag}(1,476 \mathrm{keV}, 1,505 \mathrm{keV})$ \\
\hline 1,760 (broad peak) & ${ }^{214} \mathrm{Bi}(1,765 \mathrm{keV})$ \\
\hline 2,610 (broad peak) & ${ }^{208} \mathrm{TI}(2,614 \mathrm{keV})$ \\
\hline
\end{tabular}


Table 8. Gamma-Ray Photopeak Identifications-Spectrum C (Site along Lake Road)

\begin{tabular}{l|l}
\hline \multicolumn{1}{c|}{ Energy (keV) } & \multicolumn{1}{c}{ Identification } \\
\hline 609 & ${ }^{214} \mathrm{Bi}(609 \mathrm{keV})$ \\
660 (weak) & ${ }^{137} \mathrm{Cs}(662 \mathrm{keV})$ \\
$920-960$ (weak multiplet) & $214 \mathrm{Bi}(934 \mathrm{keV}),{ }^{228} \mathrm{Ac}(911 \mathrm{keV}, 968 \mathrm{keV})$ \\
1,120 & $214 \mathrm{Bi}(1,120 \mathrm{keV})$ \\
1,450 & ${ }^{40} \mathrm{~K}(1,460 \mathrm{keV})$ \\
1,760 (broad peak) & $214 \mathrm{Bi}(1,765 \mathrm{keV})$ \\
2,520 (broad peak) & $208 \mathrm{Tl}(2,614 \mathrm{keV})$ \\
\hline
\end{tabular}

Table 9. Detection Limits for Spatially Averaged Data

\begin{tabular}{|c|c|c|}
\hline Radionuclide & $\begin{array}{c}L_{c} \\
99.9 \% \\
\text { Confidence } \\
\text { Level }\end{array}$ & $\begin{array}{c}\mathrm{L}_{\mathrm{D}} \\
99.9 \% \\
\text { Confidence } \\
\text { Level }\end{array}$ \\
\hline${ }^{60} \mathrm{Co}$ & 9.5 & $\begin{array}{l}0.13 \mathrm{pCi} / \mathrm{g}(\mathrm{u})^{\mathrm{a}} \\
0.31 \mathrm{pCi} / \mathrm{g}(\mathrm{e})^{\mathrm{b}}\end{array}$ \\
\hline${ }^{137} \mathrm{Cs}$ & 13 & $\begin{array}{l}0.38 \mathrm{pCi} / \mathrm{g}(\mathrm{u}) \\
0.74 \mathrm{pCi} / \mathrm{g}(\mathrm{e})\end{array}$ \\
\hline
\end{tabular}

a (u) values refer to activity uniformly distributed in the soil.

b (e) values apply to activity exponentially distributed in the soil. 
APPENDIX A

\section{SURVEY PARAMETERS}

Survey Site:

Survey Location:

Survey Date:

Survey Coverage:

Survey Altitude:

Aircraft Speed:

Line Spacing:

Line Length:

Line Direction:

Number of Lines:

Detector Array:

Acquisition System:

Aircraft:

Project Scientist:
Robert Emmett Ginna Nuclear Power Plant

Ontario, New York

October 1995

$10.76 \mathrm{sq} \mathrm{mi}(27.55 \mathrm{sq} \mathrm{km})$

$150 \mathrm{ft}(46 \mathrm{~m})$

70 knots $(36 \mathrm{~m} / \mathrm{s})$

$250 \mathrm{ft}(76 \mathrm{~m})$

Flight lines varied in length from $1-3.5 \mathrm{mi}(1.6-5.6 \mathrm{~km})$

North-South

Approximately 120

Eight $\mathrm{Na}(\mathrm{Tl})$ detectors $(2 \times 4 \times 16$ in)

Two $\mathrm{Na}(\mathrm{T} l)$ detectors $(2 \times 4 \times 4 \mathrm{in})$

REDAR IV

MBB BO-105 helicopter (Tail Number N40EG)

A.E. Proctor 


\section{APPENDIX B}

\section{DERIVATION OF CONVERSION FACTORS}

The relationship between the photopeak net-count rate observed at a distance $h$ above the surface and the activity of a monoenergetic gamma emitter distributed in the soil can be written as follows: ${ }^{17,18}$

$\phi=\int_{0}^{\infty} \int_{0}^{\infty} \frac{S_{\mathrm{V}}(z)}{4 \pi D^{2}} e^{-\left(\frac{\mu}{\rho}\right)_{a} \rho_{a} r_{a}} e^{-\left(\frac{\mu}{\rho}\right)_{s} \rho_{s} r_{s}}$

$2 \pi x d x d z$

where

$\phi=$ photopeak flux at the detector

$S_{V}(z)=$ activity per unit volume; usually assumed to be a function of depth in the soil $\left(\left[\gamma / \mathrm{sec}^{2} / \mathrm{cm}^{3}\right)\right.$

$D=r_{a}+r_{s}$; detector-to-source distance in the air and the soil combined $(\mathrm{cm})$

$z=$ source distribution depth in the soil (cm)

$x=$ integration variable;

$$
D=\left[x^{2}+(h+z)^{2}\right]^{1 / 2}
$$

$(\mu / \rho)_{a},(\mu / \rho)_{s}=$ air and soil mass attenuation coefficients for the monoenergetic gamma energy $\left(\mathrm{cm}^{2} / \mathrm{g}\right)$

$\rho_{a}, \rho_{s}=$ air and soil density $\left(\mathrm{g} / \mathrm{cm}^{3}\right)$

For man-made radioactive material distribution patterns, the distribution of a gamma emitter in the soil can be approximated by an exponential vertical distribution of concentration:

$$
S_{V}(z)=S_{v o} e^{-\alpha z}
$$

$S_{V O}$ is the activity per gram of soil at the surface, and $\alpha$ is the reciprocal of the relaxation depth. This implies that the representative volume of soil at a depth of $1 / \alpha$ is assumed to contain approximately 63 percent of the source's total activity. At relaxation depths of $2 / \alpha$ and $3 / \alpha$, the representative volume of soil is assumed to contain approximately 86 percent and 95 percent, respectively, of the total activity.

The effective area, $A$, represents the detector's capability or efficiency in detecting the specific gamma ray.

$$
N_{P}=A \phi
$$

$N_{p}$ is the photopeak net-count rate, and $\phi$ is the incident flux on the detector. The effective area, in general, varies as a function of the gamma-ray angle incident to the detector face and can be written as follows:

$$
A=A_{0} R(\theta)
$$

$A_{0}$ is the detector-effective area for a unit flux perpendicular to the detector face (zero degrees) $\left(\mathrm{cm}^{2}\right) . R(\theta)$ is the ratio of the detector response at an angle $\theta$ to its response at zero degrees. In practice, the effective area is measured with point radiation sources of different energies whose activities are traceable to the National Institute of Science and Technology.

Rewriting Equation B- 1 in terms of $\theta$ and $z$ and combining Equation B-4 leads to an expression which relates the measured photopeak count rate to the source activity where the conversion factor can be expressed in units of $\mathrm{cps} /\left(\gamma / \mathrm{cm}^{3}-\mathrm{s}\right)$.

$$
\frac{\left(N_{p}\right)}{S_{V 0}}=\frac{A_{0}}{2} \int_{0}^{\frac{\pi}{2}} R(\theta) \tan \theta \frac{e^{-\left(\frac{\mu}{\rho}\right)_{a} \rho_{a} h \sec \theta}}{\alpha+\left(\frac{\mu}{\rho}\right)_{s} \rho_{s} \sec \theta} d \theta
$$

For a specific isotope, the conversion factor can be changed to units of $\mathrm{cps} /\left(\mathrm{pCi} / \mathrm{cm}^{3}\right)$ by converting gamma rays per second into $\mathrm{pCi}$. This conversion depends on the branching ratio $\beta$, which is the number of gamma rays emitted per disintegration. Multiplying the expression in Equation B-5 by the soil density $\left(\mathrm{g} / \mathrm{cm}^{3}\right)$, the conversion factor can be given in units of $\mathrm{cps} /(\mathrm{pCi} / \mathrm{g})$.

The average radionuclide concentration in the top $z$ $\mathrm{cm}$ in the soil can be written as for an exponentially distributed gamma emitter as follows: 
$S_{V}^{z}=\frac{1}{z} \int_{0}^{z} S_{V 0} e^{-a z} d z=\frac{S_{V 0}}{a z}\left(1-e^{-a z}\right)$

(B-6)

By substituting Equation B-6 into Equation B-5 and dividing by the soil density, the conversion factor can be expressed in units of (pCi/g)/cps.

$$
\begin{aligned}
\frac{\left(\frac{S_{V}^{z}}{\rho_{s}}\right)}{N_{p}}= & \frac{\left(1-e^{-\alpha z}\right)}{a z}(\beta) \\
& {\left[\frac{A_{0} \rho_{s}}{2} \int_{0}^{\frac{\pi}{2}} R(\theta) \tan \theta \frac{e^{-\left(\frac{\mu}{\rho}\right)_{a} \rho_{a} h \sec \theta}}{a+\left(\frac{\mu}{\rho}\right)_{s} \rho_{s} \sec \theta} d \theta\right]^{-1} }
\end{aligned}
$$

Examples of computed minimum detectable activities and soil concentration conversion factors from point radiation sources can be found in the literature. 19,20

Estimated conversion factors can be computed for specific survey conditions through numerical integration of the previous equation. Combining these conversion factors with representative spectral background count rates and calculating Currie's detection limits yield dimensioned values of the detection limits. The limits shown in Table B-1 have been calculated for the Ginna survey using the Calvert County, Maryland, reference line as the spectral background.

(B-7) 


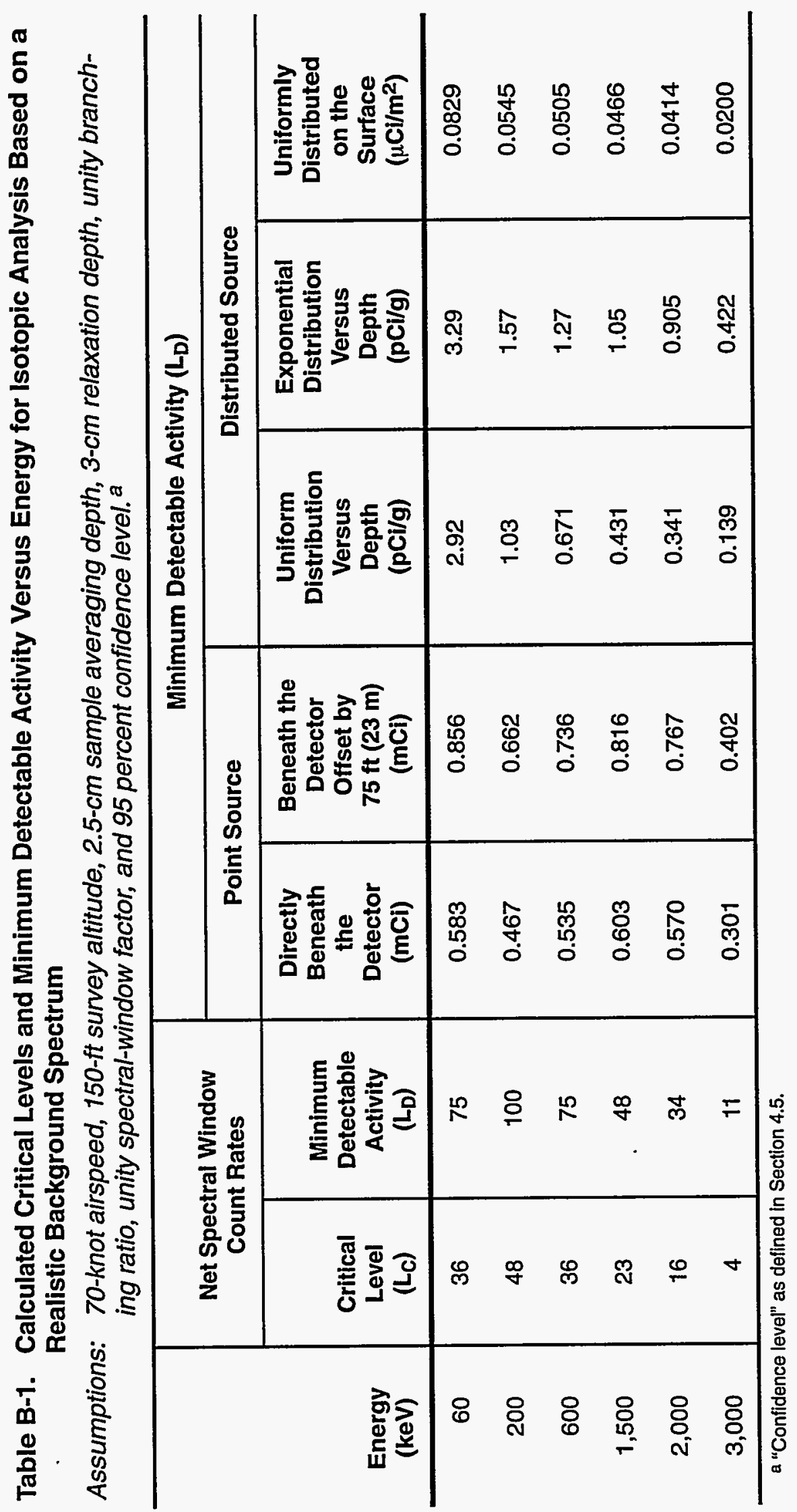




\section{REFERENCES}

1. Boyns, P.K. An Aerial Radiological Survey of the Area Surrounding the Robert Emmett Ginna Nuclear Power Plant, Ontario, New York. Report No. EGG-1183-1658, 1978; EG\&G, Las Vegas, Nevada.

2. Jobst, J.E. "Recent Advances in Airborne Radiometric Technology," Remote Sensing Technology, Proceedings of a Symposium on Remote Sensing Technology in Support of the United States Department of Energy, 23-25 February 1983. Report No. EGG-10282-1057, 1985; EG\&G/EM, Las Vegas, Nevada.

3. Radiation, Environmental Data Acquisition and Recorder System (REDAR IV) Manual. 1981; Aerial Measurements Operations, EG\&G, Las Vegas, Nevada.

4. Belian, J.; R. Dayton. NaI(Tl) Scintillation Detectors. Bicron Corporation.

5. Hendricks, T.J. "Radiation and Environmental Data Analysis Computer (REDAC) Hardware, Software and Analysis Procedures," Remote Sensing Technology, Proceedings of a Symposium on Remote Sensing Technology in Support of the United States Department of Energy, 23-25 February 1983. Report No. EGG-10282-1057, 1985; EG\&G/EM, Las Vegas, Nevada.

6. Lindeken, C.L.; K.R. Peterson; D.E. Jones; R.E. McMillen. "Geographical Variations in Environmental Radiation Background in the United States," Proceedings of the Second International Symposium on the Natural Radiation Environment, August 7-11, 1972, Houston, Texas. 1972; pp 317-332. National Technical Information Service, Springfield, Virgina.

7. Klement, Jr., A.W.; C.R. Miller; R.P. Minx; B. Shleien. Estimates of Ionizing Radiation Doses in the United States, 1960-2000. U.S. EPA Report ORP/CSD72-1, 1972; EPA, Washington, D.C.

8. Proctor, A.E. [Oral communication with M.F. Mohar, Washington Aerial Measurements Organization, Andrews Air Force Base]. 1995 October.

9. Mohr, R.A. Ground Truth Measurements at the Calvert County, Maryland Test Line. Report No. EGG-10282-2066. 1985; EG\&G/EM, Santa Barbara, California.

10. Maurer, R. An Aerial Radiological Survey of the Quad Cities Nuclear Power Station and Surrounding Area. Report No. EGG-10617-1219, 1993; EG\&G/EM, Las Vegas, Nevada.

11. Feimster, E.L. An Aerial Radiological Survey of L Lake and Steel Creek, Savannah River Site. Report No. EGG-10617-1146, 1992; EG\&G/EM, Las Vegas, Nevada.

12. Essington, E.H.; E.B. Fowler. "Distribution of Transuranic Radionuclides in Soils, A Review," Transuranics in Natural Environments, A Symposium at Gatlinburg, October 1976. NVO-178, 1977; pp 41-77.

13. Currie, L.A. "Limits for Qualitative Detection and Quantitative Determination; Application to Radiochemistry." Analytical Chemistry 40. №. 3, 1968; pp 586-593.

14. A. E Proctor [Oral communication with Peter Drysdale, NRC Resident Inspector, Robert E. Ginna Nuclear Power Plant]. 1997 January.

15. Residual Environmental Contamination from the Ginna Steam Generator Tube Rupture of 25 January 1982. SAIC Nuclear Environmental Sciences Division, Rockville, Maryland.

16. Voilleque, P. [Letter to Donald Fillion].1990 August.

17. .Environmental Radiation Measurements, Recommendations of the National Council on Radiation Protection and Measurements. Report No. 50, 1976; pp 32-34. National Council on Radiation Protection, Washington D.C. 
18. Tipton, W.J.; A.E. Fritzsche; R.J. Jaffe; A.E. Villaire. An In Situ Determination of ${ }^{241}$ Am on the Enewetak Atoll. Report No. EGG-1183-1778, 1981; EG\&G, Las Vegas, Nevada.

19. Beck, H.L.; J. DeCampo; C. Gogolak. In Situ Ge(Li) and NaI(Tl) Gamma Ray Spectrometry. Report No. HASL-258, TID-4500, 1972; U.S. AEC Health and Safety Laboratory, New York, New York.

20. Reiman, R.T. In Situ Surveys of the U. S. Department of Energy's Rocky Flats Plant, Golden, Colorado. Report No. EGG-10617-1129, 1991; EG\&G/EM, Las Vegas, Nevada. 